\title{
Death in hospital following ICU discharge: insights from the LUNG SAFE study
}

\author{
Fabiana Madotto ${ }^{1 \dagger}$, Bairbre McNicholas ${ }^{2,3 \dagger}$, Emanuele Rezoagli ${ }^{4,5}$, Tài Pham ${ }^{6,7}$, John G. Laffey ${ }^{2,3 *}$, \\ Giacomo Bellani ${ }^{4,5}$ on behalf of the LUNG SAFE Investigators and the ESICM Trials Group
}

\begin{abstract}
Background: To determine the frequency of, and factors associated with, death in hospital following ICU discharge to the ward.

Methods: The Large observational study to UNderstand the Global impact of Severe Acute respiratory FailurE study was an international, multicenter, prospective cohort study of patients with severe respiratory failure, conducted across $459 \mathrm{ICU}$ from 50 countries globally. This study aimed to understand the frequency and factors associated with death in hospital in patients who survived their ICU stay. We examined outcomes in the subpopulation discharged with no limitations of life sustaining treatments ('treatment limitations'), and the subpopulations with treatment limitations.

Results: 2186 (94\%) patients with no treatment limitations discharged from ICU survived, while 142 (6\%) died in hospital. 118 (61\%) of patients with treatment limitations survived while 77 (39\%) patients died in hospital. Patients without treatment limitations that died in hospital after ICU discharge were older, more likely to have COPD, immunocompromise or chronic renal failure, less likely to have trauma as a risk factor for ARDS. Patients that died post ICU discharge were less likely to receive neuromuscular blockade, or to receive any adjunctive measure, and had a higher pre- ICU discharge non-pulmonary SOFA score. A similar pattern was seen in patients with treatment limitations that died in hospital following ICU discharge.
\end{abstract}

Conclusions: A significant proportion of patients die in hospital following discharge from ICU, with higher mortality in patients with limitations of life-sustaining treatments in place. Non-survivors had higher systemic illness severity scores at ICU discharge than survivors.

Trial Registration: ClinicalTrials.gov NCT02010073.

Keywords: Acute hypoxemic respiratory failure, Acute respiratory distress syndrome, Hospital survival, ICU discharge, LUNG SAFE

\section{Background}

Patients that are discharged alive from the ICU are often considered to have 'survived' their critical illness, and to be in the recovery phase. However, this is now

\footnotetext{
*Correspondence: john.laffey@nuigalway.ie

${ }^{\dagger}$ Fabiana Madotto and Bairbre McNicholas: Joint First authors

${ }^{2}$ Department of Anaesthesia and Intensive Care Medicine, Galway University Hospitals, Galway, Ireland

Full list of author information is available at the end of the article
}

understood that these patients suffer ongoing increased morbidity and mortality following the acute phase of their critical illness. Indeed, one might view ICU survival as one-albeit major-of a series of hurdles in a recovery process from critical illness that can take several years. Elegant long-term follow-up studies, such as those conducted by Herridge and colleagues, show substantial ongoing functional limitations that persist up to 5 years following ARDS [1]. original author(s) and the source, provide a link to the Creative Commons licence, and indicate if changes were made. The images or other third party material in this article are included in the article's Creative Commons licence, unless indicated otherwise in a credit line to the material. If material is not included in the article's Creative Commons licence and your intended use is not permitted by statutory regulation or exceeds the permitted use, you will need to obtain permission directly from the copyright holder. To view a copy of this licence, visit http://creativecommons.org/licenses/by/4.0/. The Creative Commons Public Domain Dedication waiver (http://creativeco mmons.org/publicdomain/zero/1.0/) applies to the data made available in this article, unless otherwise stated in a credit line to the data. 
In contrast, relatively little is known about the subgroup of patients that are discharged to the ward from the ICU, but subsequently die in hospital prior to discharge. Of particular interest is the identification of potentially modifiable factors associated with in-hospital death in these patients. Patients discharged from ICU can be considered to fall into 2 groups, depending on whether limitations regarding life-sustaining treatments (referred to as 'treatment limitations') were placed at the time of discharge [2, 3]. Patients in whom treatment limitations were in place are generally considered to have a more guarded prognosis, while patients without such treatment limitations are thought to have a better prognosis $[2,3]$.

Given these issues, we wished to examine the frequency and factors associated with death in hospital following ICU discharge in patients enrolled into The Large observational study to UNderstand the Global impact of Severe Acute respiratory FailurE (LUNG SAFE) study, a prospective cohort study undertaken in 459 Intensive Care Units (ICUs) in 50 countries across 5 continents [4]. LUNG SAFE constitutes the largest cohort available of patients with acute hypoxaemic respiratory failure requiring ventilatory support. The wide geographic spread of participating ICUs, and the large patient sample size are important strengths of this study [4]. In this secondary and explorative analysis of LUNG SAFE, our primary objective was to determine the percentage of patients dying in hospital following ICU discharge, in patients with and without treatment limitation decisions in place. Secondary objectives included description of factors associated with death in both patient subgroups, with a particular focus on identifying risk factors (some of which are potentially modifiable) and related to patient management.

\section{Methods and materials Study design}

The detailed methods and protocol have been published elsewhere [4]. In brief, LUNG SAFE was an international, multicentre, prospective cohort study, with a 4-week enrolment window in the winter season [4]. The study, funded by the European Society of Intensive Care Medicine (ESICM), was endorsed by multiple national societies/networks (Acknowledgements). All participating ICUs obtained ethics committee approval, and either patient consent or ethics committee waiver of consent. National coordinators (Acknowledgements) and site investigators (Acknowledgements) were responsible for obtaining ethics committee approval and for ensuring data integrity and validity.

\section{Study population}

The study inclusion criteria for acute respiratory hypoxemic failure (AHRF) were: a $\mathrm{PaO}_{2} / \mathrm{FIO}_{2}$ of $300 \mathrm{mmHg}$ or less; new pulmonary infiltrates on chest imaging, and requirement of ventilatory support with a positive endexpiratory pressure (PEEP) of $5 \mathrm{~cm} \mathrm{H}_{2} \mathrm{O}$ or more. Exclusion criteria were: age $<16$ years or inability to obtain informed consent, where required. The study population consisted of patients fulfilling criteria for AHRF that survived their ICU stay and were discharged to a hospital ward within 90 days of ICU admission). The study population was divided into 2 groups, depending on whether or not the patient has a decision to limit life-sustaining measures (Fig. 1).

\section{Data definitions}

Our data definitions have been previously reported [4]. In the present study, ICU and hospital survival were evaluated at ICU or hospital discharge, or at day 90, whichever occurred first. For the geo-economic area definition, we used the classification we have previously reported [5].

\section{Data management and statistical analyses}

Descriptive statistics included proportions for categorical and mean (standard deviation) or median (interquartile range) for continuous variables. The amount of missing data was low as previously reported [4], and no assumptions were made for missing data. Statistical differences in proportions observed in the groups (treatment limitation, no treatment limitation) were assessed with chisquare test, or Fisher exact test according to number of expected cases. Continuous variables were compared using T-test or Wilcoxon rank sum test, according to Normal data distribution. Shapiro-Wilks test was used to assess normality in data distribution.

In order to assess statistical difference between parameters observed at ICU admission and discharge, we used Wilcoxon signed-rank test accounting for the paired nature of the data not normally distributed.

Logistic regression models were applied in order to identify predictors of hospital mortality in patients without treatment limitation. A stepwise approach was used to detect predictor of hospital mortality after ICU discharge. This approach combines forward and backward selection methods in an iterative procedure (significance level of 0.05 both for entry and retention). Potential independent predictors were: patient characteristics at baseline (age, sex, BMI, geo-economic area), chronic disease (chronic obstructive pulmonary disease (COPD), diabetes mellitus, immuno-incompetence, cardiac failure, renal failure, liver failure), presence of ARDS risk factors, ICU characteristics (number of beds, proportion 


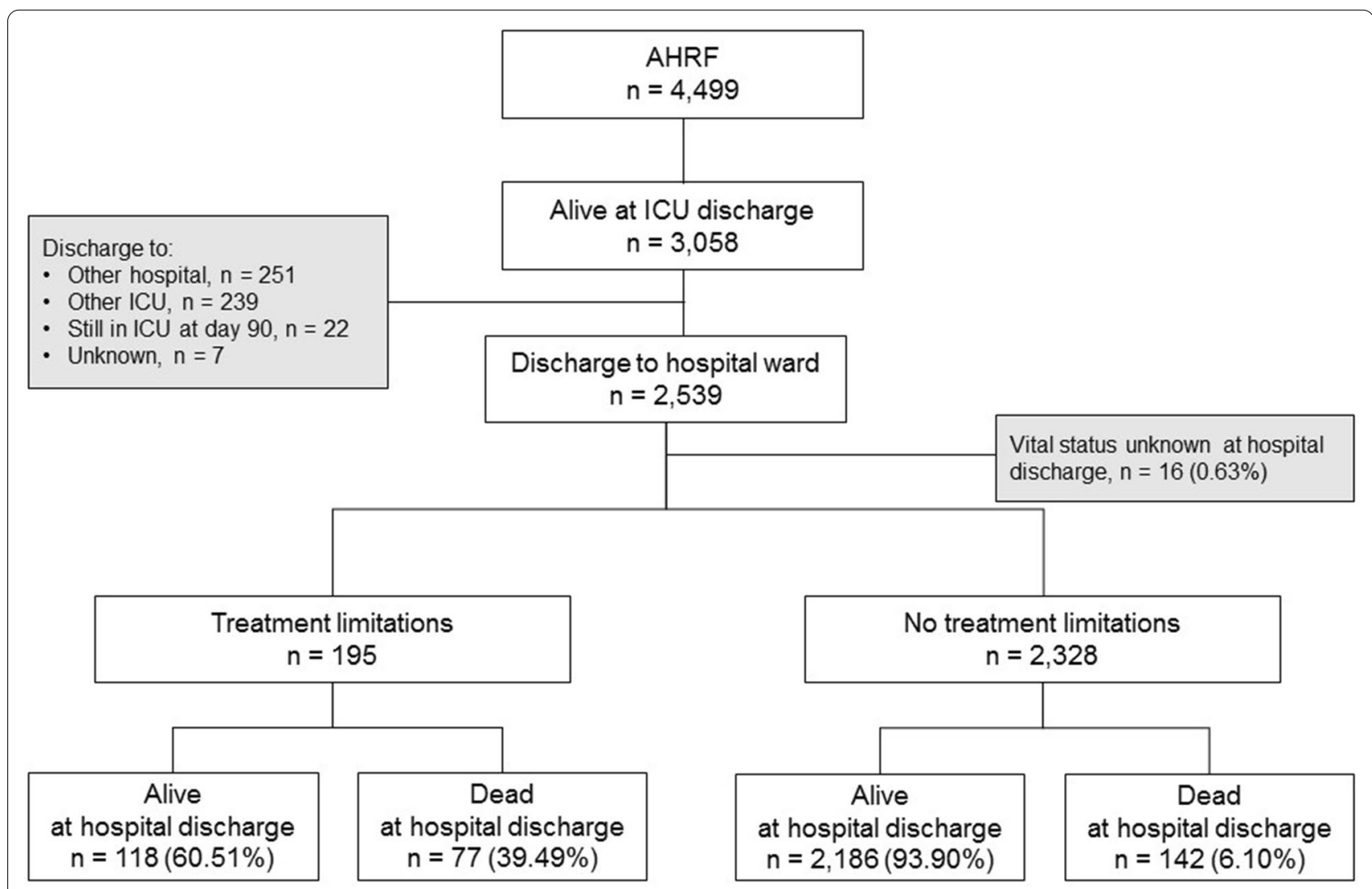

Fig. 1 Flowchart of study population subdivided into the patient groups with and without treatment limitations

of ICU beds in hospital, number of beds per physician and per nurse, academic ICU), illness severity parameters evaluated at last available day in $\mathrm{ICU}\left(\mathrm{PaO}_{2} / \mathrm{FiO}_{2}\right.$, $\mathrm{PaCO}_{2}, \mathrm{pH}$, SOFA score adjusted for missing values). Results were reported as odds ratio with 95\% confidence interval. Same approach was used on patients on invasive mechanical ventilation for at least two days during ICU stay in order to assess the possible association between ventilator parameters and hospital mortality (after ICU discharge). The list of possible independent variables used in stepwise approach also included ventilator setting observed during the last available day of IMV. Same analysis was performed on patients with a treatment limitation during ICU stay.

The Kaplan-Meier approach was applied to assess the probability of hospital survival after ICU discharge, considering censored those patients discharged alive from hospital, as well as those patients with a hospital discharge after 60 days from ICU discharge. The log-rank test was used to compare survival curves estimated in patients with or without treatment limitation. Same approach was used to assess probability of hospital survival in study population stratified in 3 groups: patients with a treatment limitation, patients without a treatment limitation and adjunctive measures used during ICU stay, patients without a treatment limitation and no adjunctive measures.

All $p$ values were two-sided, with $p$ values $<0.05$ considered as statistically significant. Statistical analyses were performed with $\mathrm{R}$, version 3.5.2 (The R Foundation for Statistical Computing) and SAS software, version 9.4 (SAS Institute, Cary, NC, USA).

\section{Results}

A total of 4499 patients had AHRF defined by a $\mathrm{PaO}_{2} /$ $\mathrm{FIO}_{2}$ of $300 \mathrm{mmHg}$ or less, new pulmonary infiltrates on chest imaging, and requirement of ventilator support with a PEEP of $5 \mathrm{~cm} \mathrm{H}_{2} \mathrm{O}$ or more (Fig. 1). Of these, 3058 (68\%) survived to ICU discharge. Of these, 2814 (92\%) did not have any treatment limitations in place, while 244 patients $(8 \%)$ did have limitations in place.

\section{Death in hospital post-ICU discharge}

2186 (94\%) of patients without treatment limitations survived to hospital discharge, while $142(6.1 \%)$ died in hospital (Fig. 1). 118 (61\%) of patients with treatment limitations survived, while 77 (39\%) patients died in hospital. Of the 39 patients (20\%) with treatment limitations 
placed on (36 patients) or before (3 patients) ICU admission, 12 died (32\%). Of the 145 patients $(74 \%)$ that had treatment limitations in place after the day of ICU admission, 62 (43\%) died in hospital following ICU discharge. 11 patients had date of limitation not available, of whom 3 died (27\%). There were no significant differences in hospital mortality rates $(p=0.18)$.

Patients that died in hospital after ICU discharge differed in a number of potentially important respects from those that survived (Table 1) being older, more likely to have COPD, immunocompromise or chronic renal failure and less likely to have trauma as a risk factor for ARDS.

\section{Illness severity factors}

Patients with no treatment limitations who died in hospital following ICU discharge had higher organ injury severity scores (Fig. 2a) compared to survivors, at both ICU admission and at ICU discharge (Table 2). SOFA scores at first day of AHRF and at last available day in ICU were higher in patients that died in hospital after ICU discharge (Table 2). This seemed to be driven by the non-pulmonary components of the SOFA score (Fig. 2b), as pulmonary organ injury severity scores did not differ between survivors and non-survivors in those without treatment limitations. Specifically, there was no difference in $\mathrm{P} / \mathrm{F}$ or $\mathrm{PaCO} 2$ on initial or last day between survivors and non-survivors (Fig. 2c, d). In addition, there was no difference in the proportion of patient with ARDS among those that survived versus those that died following ICU discharge (Table 1).

In contrast, patients with treatment limitations who died in hospital following ICU discharge had comparable systemic organ injury severity scores (Additional file 1: Figure e1A-B), but higher pulmonary organ injury severity scores (Additional file 1: Figure e1C-D) compared to survivors, at both ICU admission and at ICU discharge. ARDS recognition was lower (Additional file 1: Table S1) in non-survivors compared to survivors.

\section{Patient management factors}

Patients with no treatment limitations that survived to hospital discharge received higher levels of PEEP on the first day of invasive MV (Table 3). In contrast, on the last day of assisted ventilation in the ICU, both surviving and non-surviving patients with no treatment limitations required similar levels of ventilatory support (Table 3 ). Specifically, last day $\mathrm{FiO}_{2}$ (Fig. 3a) and peak initiatory pressures (Fig. 3b) were lower, while tidal volume, respiratory rates, dynamic compliance and minute volumes (Fig. 3c-f) were similar, in comparison to hospital survivors. Furthermore, there were no differences in the length of ICU stay between survivors and non-survivors, although the proportion of patients with long ICU stays was numerically higher in patients that survived postICU discharge (Table 1).

Similar patterns were seen in patients with treatment limitations who died in hospital (Additional file 1: Figure e2A-F). Patients with treatment limitations who died post ICU discharge had shorter ICU stays compared to those that survived (Additional file 1: Table S1).

\section{Impact of adjunctive therapies}

The frequency of neuromuscular blockade use, and of any adjunctive treatment was reduced in patients who died in hospital following ICU discharge (Table 4). Use adjunctive measures was independently associated with reduced hospital mortality in a multivariate logistic regression model (Table 5).

\section{Impact of geo-economic area}

Patients from the Non-European-high income area with no treatment limitations had higher SOFA scores at ICU discharge than patients from Europe or from Middle Income countries (Table 5). However, SOFA scores at day 10 post ICU admission were not different across the regions. In patients without treatment limitations, ward mortality ratios were not different $(p=0.2086)$ between geographic areas (Table 1). In patients with treatment limitations of LSMs, ward mortality ratios were significantly lower in middle income countries $(17.2 \%)$ compared to both European-High $(41.5 \% ; p=0.0160)$ and Non-European-High $(46.7 \%, p=0.0071)$ income countries (Table 1 and Additional file 1: Table S1).

\section{Factors associated with hospital death post ICU discharge}

Length of ICU stay was similar in patients who survived to hospital discharge and those that died, in patients without treatment limitations (Fig. 4a). In contrast, patients with treatment limitations who died post ICU discharge had shorter ICU stays compared to those that survived (Additional file 1: Table S1). Hospital survival rates post ICU discharge were significantly lower in patients that had treatment limitations, compared to those with no limitations (Fig. 4b). In patients without treatment limitations, there were more deaths following ICU discharge in patients who received no adjunctive treatment as part of their ARDS management (Fig. 4c). The majority deaths for patients with limitations in lifesustaining therapies occurred within 10 days of discharge from the ICU (Fig. 4b).

In a multivariate logistic regression model Factors associated with increased hospital mortality in patients with no limitations of life sustaining measures included age, adjusted SOFA score on the last available day in ICU, and immune-incompetence. Duration of ICU stay was also associated with hospital mortality post ICU discharge in 
Table 1 Characteristics of study subpopulation with no treatment limitations at ICU discharge according to vital status at hospital discharge.

\begin{tabular}{|c|c|c|c|c|}
\hline & Alive $N=2186$ & Dead $N=142$ & Total $N=2328$ & $p$ value \\
\hline Male, n (\%) & $1363(62.35)$ & $93(65.49)$ & $1,456(62.49)$ & 0.4536 \\
\hline Age (years), mean $\pm S D$ & $60.03 \pm 16.34$ & $68.70 \pm 15.71$ & $60.56 \pm 16.43$ & $<.0001$ \\
\hline Geographic area & & & & 0.2086 \\
\hline European high income countries & $1207(55.22)$ & $88(61.97)$ & $1295(55.63)$ & \\
\hline Non-European high income countries & $655(29.96)$ & $33(23.24)$ & $688(29.55)$ & \\
\hline Middle income countries & $324(14.82)$ & $21(14.79)$ & $345(14.82)$ & \\
\hline $\mathrm{BMI}\left(\mathrm{kg} / \mathrm{m}^{2}\right)$, mean $\pm \mathrm{SD}$ & $27.92 \pm 7.72$ & $26.57 \pm 6.03$ & $27.84 \pm 7.63$ & 0.1389 \\
\hline Length of ICU stay (days) from AHRF onset, median [IQR] & $8.00[5.00-16.00]$ & $10.00[6.00-16.00]$ & $9.00[5.00-16.00]$ & 0.1162 \\
\hline Length of ICU stay > 28 days from AHRF onset, $n(\%)$ & $226(10.34)$ & $8(5.63)$ & $234(10.05)$ & 0.0708 \\
\hline Length of ICU stay (days) from admission, median [IQR] & $10.00[5.00-18.00]$ & $10.50[7.00-18.00]$ & $10.00[6.00-18.00]$ & 0.0984 \\
\hline ARDS during ICU stay, $n(\%)$ & $1414(64.68)$ & $93(65.49)$ & $1507(64.73)$ & 0.8451 \\
\hline Clinical recognition of ARDS during ICU stay, $n$ (\%) & $925(42.31)$ & $61(42.96)$ & $986(42.35)$ & 0.8806 \\
\hline \multicolumn{5}{|l|}{ Chronic disease $^{\mathrm{a}}, n(\%)$} \\
\hline COPD & $492(22.51)$ & $43(30.28)$ & $535(22.98)$ & 0.0328 \\
\hline Diabetes mellitus & $501(22.92)$ & $36(25.35)$ & $537(23.07)$ & 0.5047 \\
\hline Immune-incompetence (all-types) & $344(15.74)$ & $40(28.17)$ & $384(16.49)$ & 0.0001 \\
\hline Chronic cardiac failure & $241(11.02)$ & $19(13.38)$ & $260(11.17)$ & 0.3878 \\
\hline Chronic renal failure & $229(10.48)$ & $23(16.10)$ & $252(10.82)$ & 0.0335 \\
\hline Chronic liver failure & $42(1.92)$ & $5(3.52)$ & $47(2.02)$ & 0.2054 \\
\hline Risk factors for ARDS, $n$ (\%) & & & & 0.3586 \\
\hline None & $373(17.06)$ & $22(15.49)$ & $385(16.97)$ & \\
\hline Only non-pulmonary & $448(20.49)$ & $36(25.35)$ & $484(20.79)$ & \\
\hline Only pulmonary & $1110(50.32)$ & $72(50.70)$ & $1172(50.34)$ & \\
\hline Both & $265(12.12)$ & $12(8.45)$ & $277(11.90)$ & \\
\hline \multicolumn{5}{|l|}{ Risk factors for ARDS ${ }^{\mathrm{a}}, n(\%)$} \\
\hline Pneumonia & $1089(49.82)$ & $78(54.93)$ & $1167(50.13)$ & 0.2377 \\
\hline Extra-pulmonary sepsis & $301(13.77)$ & $16(18.31)$ & $327(14.05)$ & 0.1313 \\
\hline Aspiration of gastric contents & $289(13.22)$ & $13(9.15)$ & $302(12.97)$ & 0.1624 \\
\hline Pancreatitis & $30(1.78)$ & $4(2.82)$ & $43(1.85)$ & 0.3304 \\
\hline Trauma or pulmonary contusion & $152(6.95)$ & $2(1.41)$ & $154(6.62)$ & 0.0100 \\
\hline Inhalation & $37(1.69)$ & $4(2.82)$ & $41(1.76)$ & 0.3120 \\
\hline Non cardiogenic shock & $124(5.67)$ & $11(7.75)$ & $135(5.80)$ & 0.3055 \\
\hline Drowning & $0(0.00)$ & $0(0.00)$ & $0(0.00)$ & - \\
\hline Drug overdose & $55(2.52)$ & $3(2.11)$ & $58(2.49)$ & 1.0000 \\
\hline Blood transfusion & $77(3.52)$ & $6(4.23)$ & $83(3.57)$ & 0.6616 \\
\hline Other risk factors & $101(4.62)$ & $5(3.52)$ & $106(4.55)$ & 0.5426 \\
\hline \multicolumn{5}{|l|}{ ICU characteristics } \\
\hline Academic hospital, $n$ (\%) & $1660(78.01)$ & $106(75.71)$ & $1766(77.87)$ & 0.5267 \\
\hline$\%$ of ICU on hospital beds, median [IQR] & $2.60[1.56-4.17]$ & $2.61[1.56-4.35]$ & $2.60[1.56-4.22]$ & 0.7886 \\
\hline Beds per physician, median [IQR] & $4.83[2.67-10.00]$ & $4.67[2.67-9.00]$ & $4.83[2.67-10.00]$ & 0.4145 \\
\hline Beds per nurse, median [IQR] & $1.50[1.00-2.00]$ & $1.31[1.00-2.00]$ & $1.50[1.00-2.00]$ & 0.0511 \\
\hline
\end{tabular}

ARDS acute respiratory distress syndrome, $B M I$ body mass index, COPD chronic obstructive pulmonary disease, ICU intensive care unit, IQR interquartile range [first and third quartile], $S D$ standard deviation

a Sum of percentages is greater than $100 \%$, because patient could have more than one chronic disease/risk factor. 

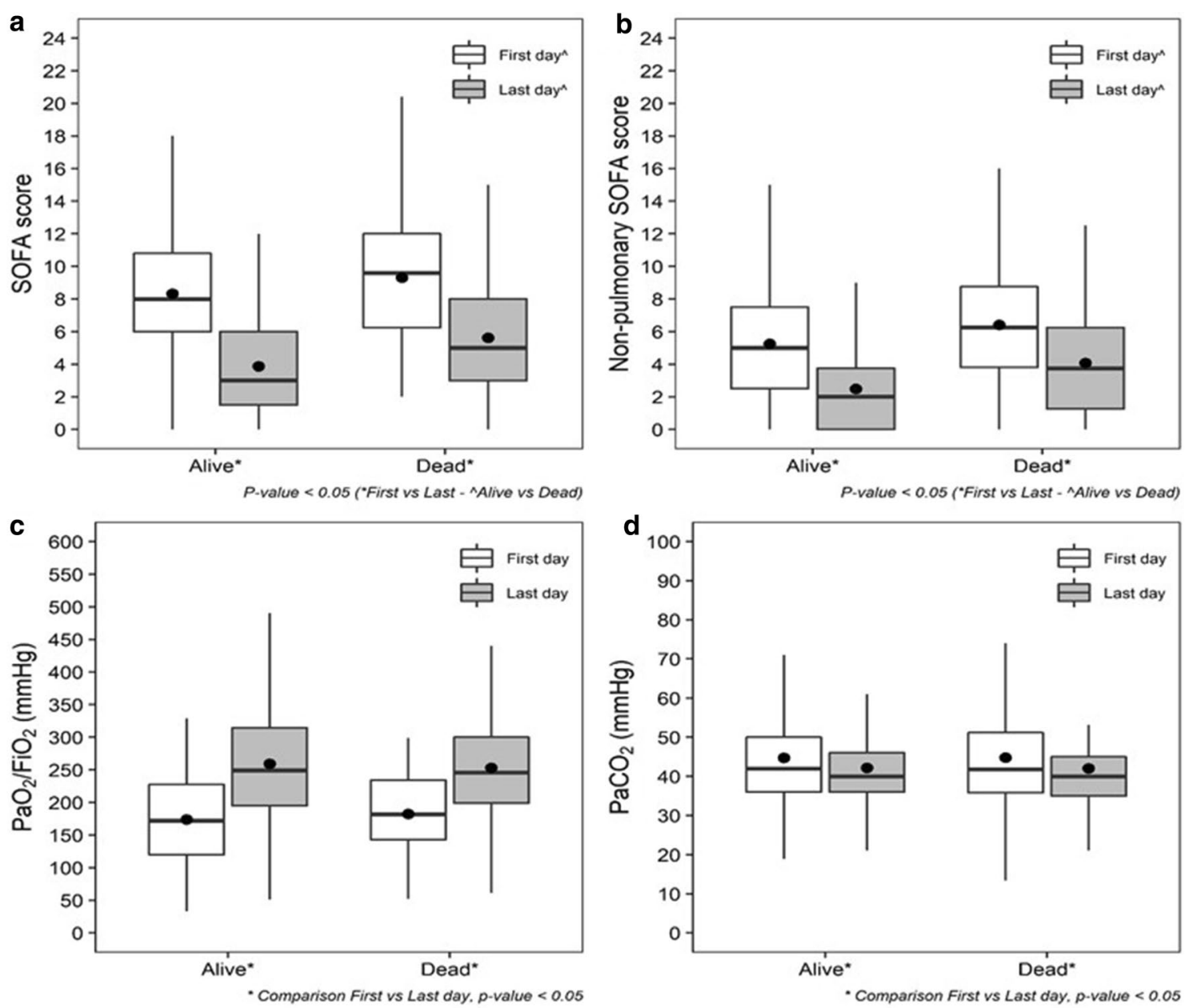

Fig. 2 Patients with no treatment limitations who die in hospital following ICU discharge have higher overall SOFA scores (a), which appeared to be due to higher systemic organ injury severity scores $(\mathbf{b})$ as pulmonary organ injury severity scores $(\mathbf{c}, \mathbf{d})$ were similar, compared to survivors, at both ICU admission and at ICU discharge

patients that received at least 2 days of invasive mechanical ventilation (Table 6). Factors associated with hospital mortality in patients with treatment limitations at ICU discharge are presented in Additional file 1: Table S5.

\section{Discussion}

In the current study, we found that $94 \%$ of patients without limitations of life sustaining therapy that were discharged from ICU stay survived to hospital discharge, while $61 \%$ of patients who had treatment limitations in place also survived to hospital discharge. Patients without treatment limitations that died in hospital after ICU discharge were older, and more likely to have COPD, immunocompromise or chronic renal failure. They were less likely to have trauma as a risk factor for ARDS, or to receive neuromuscular blockade or any adjunctive measure. An important-and unexpected-finding was that even though these patients were critically ill due to ARDS, it was the non-pulmonary components of their organ dysfunction that was associated with risk of death in hospital following ICU discharge, while the derangement of oxygenation at ICU admission was not. In addition, our finding that non-survivors received less adjunctive therapies than survivors, raises important questions on whether the low implementation of these measures might contribute to some of the long-term ARDS mortality. Understanding the factors associated with death in hospital following ICU discharge may allow us to focus efforts on these issues in order to improve outcomes.

\section{Factors contributing to death post ICU discharge}

Our finding of a $6 \%$ mortality post ICU discharge in patients with acute hypoxaemic respiratory failure is at the lower end of a range of $6-25 \%$ hospital mortality rates reported in ICU survivors in earlier studies [6-8]. 
Table 2 IIIness severity in study subpopulation with no treatment limitations at ICU discharge stratified by vital status at hospital discharge

\begin{tabular}{|c|c|c|c|c|}
\hline Parameter & Alive $N=2186$ & Dead $N=142$ & Total $N=2328$ & $p$ value \\
\hline \multicolumn{5}{|l|}{ IIIness severity at 1st day of AHRF } \\
\hline ARDS, n (\%) & $1,242(56.82)$ & $76(53.52)$ & $1,318(56.62)$ & 0.4427 \\
\hline \multicolumn{5}{|l|}{ Gas exchange } \\
\hline $\mathrm{P}_{\mathrm{a}} \mathrm{O}_{2} / \mathrm{FiO}_{2}(\mathrm{mmHg})$, mean $\pm \mathrm{SD}$ & $173.81 \pm 66.30$ & $182.49 \pm 63.28$ & $174.34 \pm 66.14$ & 0.1032 \\
\hline $\mathrm{SpO}_{2}(\%)$, median $[\mathrm{IQR}]$ & $96.0[94.0-98.0]$ & 96.0 [94.0-98.0] & $96.0[94.0-98.0]$ & 0.7613 \\
\hline $\mathrm{P}_{\mathrm{a}} \mathrm{CO}_{2}(\mathrm{mmHg})$, mean $\pm \mathrm{SD}$ & $45.34 \pm 14.88$ & $44.80 \pm 14.40$ & $45.31 \pm 14.85$ & 0.8351 \\
\hline $\mathrm{pH}$, mean $\pm \mathrm{SD}$ & $7.35 \pm 0.10$ & $7.35 \pm 0.10$ & $7.35 \pm 0.10$ & 0.9699 \\
\hline Adjusted SOFA scores, mean \pm SD & $8.33 \pm 3.72$ & $9.30 \pm 3.58$ & $8.39 \pm 3.72$ & 0.0010 \\
\hline \multicolumn{5}{|c|}{ IIIness severity at last available day in ICU } \\
\hline ARDS, $n(\%)$ & $132(7.65)$ & $8(7.14)$ & $140(7.62)$ & 0.8452 \\
\hline \multicolumn{5}{|l|}{ Gas exchange } \\
\hline \multicolumn{5}{|l|}{$\mathrm{P}_{\mathrm{a}} \mathrm{O}_{2} / \mathrm{FiO}_{2}(\mathrm{mmHg})$} \\
\hline Mean $\pm S D$ & $259.00 \pm 91.83$ & $252.83 \pm 86.61$ & $258.58 \pm 91.47$ & 0.7798 \\
\hline Available data, $n(\%)$ & $1163(53.20)$ & $85(59.86)$ & $1248(53.61)$ & 0.1232 \\
\hline \multicolumn{5}{|l|}{$\mathrm{SpO}_{2}(\%)$} \\
\hline Median $[\mathrm{IQR}]$ & $97.0[95.0-98.0]$ & 97.0 [95.0-99.0] & $97.0[95.0-98.0]$ & 0.7263 \\
\hline Available data, $n(\%)$ & $1381(63.17)$ & $89(62.68)$ & $1470(63.14)$ & 0.9050 \\
\hline \multicolumn{5}{|l|}{$\mathrm{P}_{\mathrm{a}} \mathrm{CO}_{2}(\mathrm{mmHg})$} \\
\hline Mean $\pm S D$ & $42.40 \pm 10.97$ & $42.01 \pm 11.49$ & $42.38 \pm 10.99$ & 0.6008 \\
\hline Available data, $n(\%)$ & $1265(57.87)$ & $90(63.38)$ & $1355(58.20)$ & 0.1969 \\
\hline \multicolumn{5}{|l|}{$\mathrm{pH}$ (unit) } \\
\hline Mean \pm SD & $7.43 \pm 0.05$ & $7.43 \pm 0.06$ & $7.43 \pm 0.06$ & 0.4129 \\
\hline Available data, $n(\%)$ & $1271(58.14)$ & $90(63.38)$ & $1361(58.46)$ & 0.2197 \\
\hline \multicolumn{5}{|c|}{ Adjusted non-pulmonary SOFA scores, mean \pm SD } \\
\hline Mean $\pm S D$ & $2.49 \pm 2.75$ & $4.08 \pm 3.37$ & $2.59 \pm 2.82$ & $<.0001$ \\
\hline Available data, $n(\%)$ & $1337(61.16)$ & $97(68.31)$ & $1434(61.60)$ & 0.0897 \\
\hline \multicolumn{5}{|l|}{ Adjusted SOFA scores, mean \pm SD } \\
\hline Mean \pm SD & $3.87 \pm 3.16$ & $5.62 \pm 3.71$ & $3.99 \pm 3.60$ & $<.0001$ \\
\hline Available data, $n(\%)$ & $1341(61.34)$ & $97(68.31)$ & $1438(61.77)$ & 0.0979 \\
\hline
\end{tabular}

$A R D S$ acute respiratory distress syndrome, $\mathrm{FiO}_{2}$ fraction of inspired oxygen, $I B W$ ideal body weight, ICU intensive care unit, $I Q R$ interquartile range [first and third quartile], $\mathrm{P}_{a} \mathrm{CO}_{2}$ partial pressure arterial carbon dioxide, $P_{a} \mathrm{O}_{2}$ partial pressure arterial oxygen, $P E E P$ positive end-expiratory pressure, $P I P$ peak inspiratory pressure, $S D$ standard deviation, SOFA sequential organ failure assessment.

However, it remains higher than other studies of ICU survivors where it has ranged from $3 \%$ in patients at risk for ARDS to 4\% in all ICU patients without limitations in life sustaining therapies $[9,10]$. In this regard it is important to remember that the LUNG SAFE population constitutes a more severely ill patient cohort, with patients all fulfilling criteria for severe hypoxaemia requiring assisted ventilation.

Identifying risk factors in patients who are likely to die in hospital following ICU discharge may allow us to focus efforts on these factors (if modifiable) in order to improve outcomes, either prior to or following ICU discharge. In this study, we found that patients dying post ICU discharge were systemically sicker as indicated by non-pulmonary SOFA at ICU discharge. Sepsis is a frequent cause of later deaths in patients with ARDS [11], which may be consistent with our finding of a higher non-pulmonary SOFA score for patients that died post ICU discharge. In contrast, pulmonary factors, including initial ARDS severity or respiratory status at weaning from invasive ventilation, were not associated with hospital mortality post ICU discharge.

In regard to patient management, patients that received either neuromuscular blockade use or the use of any adjunct, were more likely to survive post ICU discharge. However, this finding needs to be balanced against our prior findings showing that ICU survival in patient receiving adjunctive therapies was lower [12], raising the potential that this finding may reflect an alteration in the pattern of patients dying in the ICU versus the wards, 
Table 3 Ventilator setting in patients with no treatment limitations at ICU discharge who received invasive MV for at least 2 days (from AHRF onset) stratified by vital status at hospital discharge

\begin{tabular}{|c|c|c|c|c|}
\hline Parameter & Alive $N=2186$ & Dead $N=142$ & Total $N=2328$ & $p$ value \\
\hline Patients on IMV at 1st and 2nd day, n (\%) & $1545(70.68)$ & $111(78.17)$ & $1656(71.13)$ & 0.0562 \\
\hline Last day on IMV (with collected data), median [IQR] & $7[3-20]$ & $7[3-10]$ & $7[3-10]$ & 0.7307 \\
\hline Non-invasive Mechanical Ventilation after IMV, n (\%) & $144(9.32)$ & $7(6.31)$ & $151(9.12)$ & 0.2866 \\
\hline \multicolumn{5}{|l|}{ Ventilator setting at 1st day of Invasive MV } \\
\hline Controlled ventilation, $n(\%)$ & $1081(71.21)$ & $76(69.72)$ & $1157(7111)$ & 0.7407 \\
\hline $\mathrm{FiO}_{2}$, median $[\mathrm{IQR}]$ & $0.60[0.40-0.80]$ & $0.50[0.40-0.70]$ & $0.57[0.40-0.80]$ & 0.1899 \\
\hline Set respiratory rate (breaths/min), mean $\pm S D$ & $17.92 \pm 5.83$ & $17.66 \pm 5.38$ & $17.90 \pm 5.80$ & 0.7580 \\
\hline Total respiratory rate (breaths/min), mean \pm SD & $19.74 \pm 6.14$ & $19.51 \pm 5.84$ & $19.73 \pm 6.12$ & 0.7573 \\
\hline Tidal volume (ml/kg IBW), mean \pm SD & $7.77 \pm 1.83$ & $7.78 \pm 1.88$ & $7.77 \pm 1.84$ & 0.6565 \\
\hline High tidal volume (> 8 ml/kg IBW), $n$ (\%) & $543(36.86)$ & $42(40.00)$ & $585(37.07)$ & 0.5203 \\
\hline Dynamic compliance $\left(\mathrm{ml} / \mathrm{cmH}_{2} \mathrm{O}\right)$, mean $\pm \mathrm{SD}$ & $33.35 \pm 23.96$ & $32.23 \pm 23.04$ & $33.27 \pm 23.89$ & 0.2753 \\
\hline $\operatorname{PEEP}\left(\mathrm{cmH}_{2} \mathrm{O}\right)$, mean $\pm \mathrm{SD}$ & $8.12 \pm 3.21$ & $7.40 \pm 2.85$ & $8.07 \pm 3.19$ & 0.0095 \\
\hline $\mathrm{PIP}\left(\mathrm{cmH}_{2} \mathrm{O}\right)$, mean $\pm \mathrm{SD}$ & $26.04 \pm 7.99$ & $25.50 \pm 8.02$ & $26.01 \pm 7.99$ & 0.5395 \\
\hline Plateau pressure measured, $\mathrm{n}(\%)$ & $489(31.65)$ & $33(29.73)$ & $522(31.52)$ & 0.6740 \\
\hline Plateau pressure $\left(\mathrm{cmH}_{2} \mathrm{O}\right)$, mean $\pm \mathrm{SD}$ & $21.50 \pm 5.62$ & $21.73 \pm 6.27$ & $21.52 \pm 5.66$ & 0.9205 \\
\hline Driving pressure $\left(\mathrm{cmH}_{2} \mathrm{O}\right)$, mean $\pm \mathrm{SD}$ & $13.19 \pm 5.03$ & $14.64 \pm 5.81$ & $13.28 \pm 5.09$ & 0.1699 \\
\hline Minute ventilation $(1 / \mathrm{min})$, mean $\pm S D$ & $9.32 \pm 2.87$ & $9.06 \pm 3.07$ & $9.30 \pm 2.89$ & 0.1545 \\
\hline Standardized minute ventilation ( $1 /$ min), mean \pm SD & $10.43 \pm 4.45$ & $9.96 \pm 3.94$ & $10.40 \pm 4.42$ & 0.4408 \\
\hline \multicolumn{5}{|l|}{ Ventilator setting at last available day of Invasive MV in ICU } \\
\hline Controlled ventilation, $n(\%)$ & $384(25.35)$ & $25(23.15)$ & $409(25.20)$ & 0.6112 \\
\hline \multicolumn{5}{|l|}{$\mathrm{FiO}_{2}$} \\
\hline Median [IQR] & $0.40[0.35-0.45]$ & $0.40[0.30-0.40]$ & $0.40[0.35-0.45]$ & 0.0309 \\
\hline Available data, $n(\%)$ & $1501(97.15)$ & $107(96.40)$ & $1608(97.10)$ & 0.5586 \\
\hline \multicolumn{5}{|l|}{ Total respiratory rate (breaths/min) } \\
\hline Mean \pm SD & $20.21 \pm 12.15$ & $20.91 \pm 6.76$ & $20.26 \pm 11.86$ & 0.1920 \\
\hline Available data, $n(\%)$ & $1499(97.02)$ & $109(98.20)$ & $1608(97.10)$ & 0.7674 \\
\hline \multicolumn{5}{|l|}{ Tidal volume (ml/kg IBW) } \\
\hline High tidal volume (> 8 ml/kg IBW), n (\%) & $602(42.82)$ & $42(42.00)$ & $644(42.76)$ & 0.8733 \\
\hline Mean \pm SD & $7.95 \pm 2.06$ & $7.89 \pm 2.04$ & $7.95 \pm 2.06$ & 0.9763 \\
\hline Available data, $n(\%)$ & $1406(91.00)$ & 100 (90.09) & $1506(90.94)$ & 0.7461 \\
\hline \multicolumn{5}{|l|}{ Dynamic compliance $\left(\mathrm{ml} / \mathrm{cmH}_{2} \mathrm{O}\right)$} \\
\hline Mean \pm SD & $49.39 \pm 45.70$ & $48.72 \pm 30.39$ & $49.35 \pm 44.84$ & 0.1701 \\
\hline Available data, $n(\%)$ & $1344(86.99)$ & $96(86.49)$ & $1440(86.96)$ & 0.8790 \\
\hline \multicolumn{5}{|l|}{ PEEP $\left(\mathrm{cmH}_{2} \mathrm{O}\right)$} \\
\hline Mean \pm SD & $6.66 \pm 2.43$ & $6.26 \pm 1.95$ & $6.63 \pm 2.40$ & 0.0597 \\
\hline Available data, $n(\%)$ & $1496(96.83)$ & $106(95.50)$ & $1602(96.74)$ & 0.4043 \\
\hline \multicolumn{5}{|l|}{$\mathrm{PIP}\left(\mathrm{cmH}_{2} \mathrm{O}\right)$} \\
\hline Mean \pm SD & $20.17 \pm 7.16$ & $18.51 \pm 7.01$ & $20.06 \pm 7.16$ & 0.0079 \\
\hline Available data, $n(\%)$ & $1395(90.29)$ & $99(89.19)$ & $1494(90.22)$ & 0.7058 \\
\hline \multicolumn{5}{|l|}{ Minute ventilation (I/min) } \\
\hline Mean \pm SD & $9.65 \pm 4.08$ & $9.56 \pm 3.25$ & $9.64 \pm 4.03$ & 0.9026 \\
\hline Available data, $n(\%)$ & $1447(93.66)$ & $103(92.79)$ & $1550(93.60)$ & 0.7194 \\
\hline \multicolumn{5}{|l|}{ Standardized minute ventilation (I/min) } \\
\hline Mean \pm SD & $10.11 \pm 4.93$ & $10.04 \pm 4.00$ & $10.10 \pm 4.87$ & 0.7355 \\
\hline Available data, $n$ (\%) & $1257(81.36)$ & $92(82.88)$ & $1349(81.46)$ & 0.6899 \\
\hline
\end{tabular}

$\mathrm{FiO}_{2}$ fraction of inspired oxygen, IBW ideal body weight, IMV invasive mechanical ventilation, IQR interquartile range [first and third quartile], $P E E P$ positive endexpiratory pressure, PIP peak inspiratory pressure, SD standard deviation 

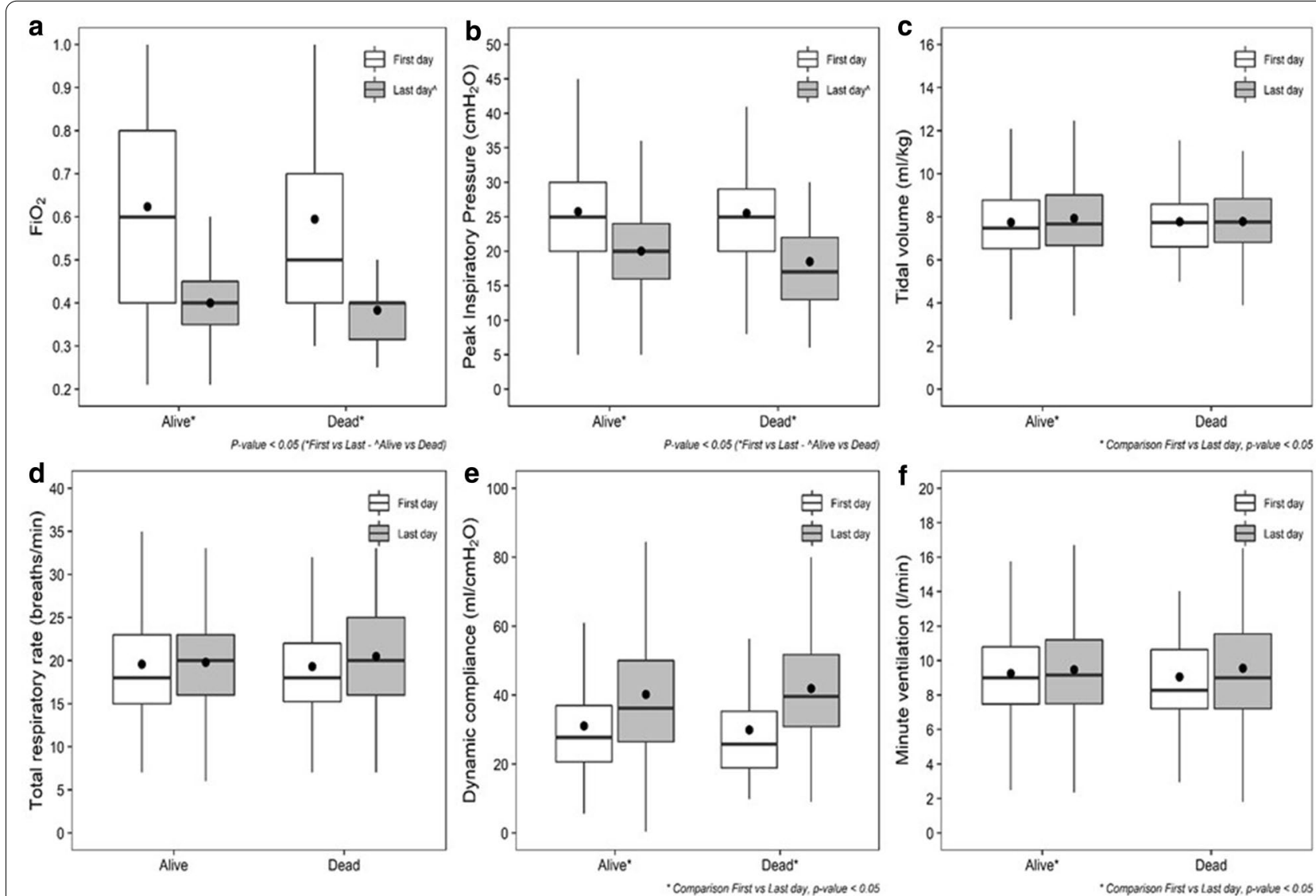

Fig. 3 Patients with no treatment limitations who die in hospital require comparable or lower degrees of ventilatory support on the last day of assisted ventilation in the ICU compared to survivors at ICU discharge. Specifically, last day $\mathrm{FiO}_{2}$ (a) and peak initiatory pressures (b) were lower, while tidal volume, respiratory rates, dynamic compliance and minute volumes (c-f) were similar, in comparison to hospital survivors

Table 4 Adjunctive measures performed during ICU stay in study subpopulation with no treatment limitations at ICU discharge stratified by vital status at hospital discharge

\begin{tabular}{|c|c|c|c|c|}
\hline Parameter & Alive $N=2186$ & Dead $N=142$ & Total $N=2328$ & $p$ value \\
\hline Neuromuscular blockade, $n$ (\%) & $304(13.91)$ & $8(5.63)$ & $312(13.40)$ & 0.0050 \\
\hline Recruitment maneuvers, $n(\%)$ & $305(13.95)$ & $14(9.86)$ & $319(13.70)$ & 0.1693 \\
\hline Prone positioning, $n(\%)$ & $100(4.57)$ & $2(1.41)$ & $102(4.38)$ & 0.0741 \\
\hline $\mathrm{ECMO}, n(\%)$ & $30(1.37)$ & $0(0.00)$ & $30(1.29)$ & 0.1600 \\
\hline Inhaled vasodilators, n (\%) & $126(5.76)$ & $7(4.93)$ & $133(5.71)$ & 0.6781 \\
\hline HFOV, $n(\%)$ & $27(1.24)$ & $0(0.00)$ & $27(1.16)$ & 0.1828 \\
\hline None of above adjunctive measures, $n(\%)$ & $1571(71.87)$ & $116(81.69)$ & $1687(72.47)$ & 0.0111 \\
\hline
\end{tabular}

ECMO extra corporeal membrane oxygenation, HFOV high frequency oscillatory ventilation

rather than a true association with improved patient outcome.

The duration of ICU stay was similar in patients that survived following ICU discharge compared to those that died in-hospital, with the proportion of longer ICU stay patients significantly higher in survivors. In patients with treatment limitations, non-survivors actually had shorter ICU stays compared to survivors. This finding appears to rule out the potential for patients that die post ICU discharge to have had longer durations of critical illness compared to patients that survive to hospital discharge. 
Table 5 SOFA Scores and Outcomes in patients with no treatment limitations by major Geo-Economic Area

\begin{tabular}{|c|c|c|c|c|}
\hline Parameter & $\begin{array}{l}\text { Alive } \\
N=2186\end{array}$ & $\begin{array}{l}\text { Dead } \\
N=142\end{array}$ & $\begin{array}{l}\text { Total } \\
N=2328\end{array}$ & $p$ value \\
\hline \multicolumn{5}{|l|}{ IIIness severity at last available day in ICU } \\
\hline \multicolumn{5}{|c|}{ Adjusted non-pulmonary SOFA scores, median [1st-3rd quartile] } \\
\hline European high income countries $(n=1295)$ & $\begin{array}{l}1.25 \\
{[0.00-3.00]}\end{array}$ & $\begin{array}{l}3.75 \\
{[1.25-5.00]}\end{array}$ & $\begin{array}{l}1.25 \\
{[0.00-3.75]}\end{array}$ & $<.0001$ \\
\hline Non-European high income countries $(n=688)$ & $\begin{array}{l}3.00 \\
{[1.00-5.00]^{*}}\end{array}$ & $\begin{array}{l}7.00 \\
{[3.75-9.00]}\end{array}$ & $\begin{array}{l}3.00 \\
{[1.00-5.00]}\end{array}$ & 0.0002 \\
\hline Middle income countries $(n=345)$ & $\begin{array}{l}1.67 \\
{[0.00-4.00]^{\circ}}\end{array}$ & $\begin{array}{l}2.00 \\
{[0.00-5.00]}\end{array}$ & $\begin{array}{l}1.67 \\
{[0.00-4.00]}\end{array}$ & 0.6691 \\
\hline$p$ value (comparison among areas) & $<.0001$ & 0.0046 & $<.0001$ & \\
\hline \multicolumn{5}{|l|}{ IIIness severity on Day 10 in ICU } \\
\hline \multicolumn{5}{|c|}{ Adjusted non-pulmonary SOFA scores, median [1st-3rd quartile] } \\
\hline European high income countries $(n=1295)$ & $\begin{array}{l}1.67 \\
{[0.00-3.00]}\end{array}$ & $\begin{array}{l}4.0 \\
{[2.5-5.00]}\end{array}$ & $\begin{array}{l}1.67 \\
{[0.00-3.75]}\end{array}$ & 0.0076 \\
\hline Non-European high income countries $(n=688)$ & $\begin{array}{l}2.00 \\
{[0.00-5.00]^{*}}\end{array}$ & $\begin{array}{l}5.63 \\
{[3.75-9.00]}\end{array}$ & $\begin{array}{l}2.75 \\
{[0.00-5.00]}\end{array}$ & 0.0160 \\
\hline Middle income countries $(n=345)$ & $\begin{array}{l}2.00 \\
{[0.00-4.00]^{\circ}}\end{array}$ & $\begin{array}{l}2.50 \\
{[0.00-6.50]}\end{array}$ & $\begin{array}{l}2.00 \\
{[0.00-5.00]}\end{array}$ & 0.8256 \\
\hline$p$ value (comparison among areas) & 0.2436 & 0.3817 & 0.1790 & \\
\hline
\end{tabular}

${ }^{*} p$ value $<0.05$, comparison with European high-income countries

${ }^{\circ} p$ value $<0.05$, comparison with Non-European high-income countries

\section{Impact of limitation of care}

Our findings suggest that the likelihood of hospital survival post-ICU discharge varies greatly depending on whether or not treatment limitations are in place. This finding is consistent with previous studies showing that the presence of limitations of life sustaining therapies is the most important factor in predicting death post ICU admission [2].

The majority of decisions to limit of life sustaining therapies were made after development of AHRF. Interestingly, hospital survival post ICU discharge in patient with a treatment limitation decision was encouragingly high at $61 \%$, while the timing of placement of treatment limitations didn't significantly affect the mortality rate.

Increased age and the presence of active or hematologic neoplasm, immune suppression, chronic liver failure and indices of greater illness severity were associated with limitation of care, consistent with prior findings [10]. Overall, there were similarities between the factors associated with patient outcome, and those associated with limitation of care. This may be consistent with the fact that death in the ICU frequently occurs in the context of decisions to limit life sustaining therapy due to perceived futility $[13,14]$. Of interest ARDS recognition rates in patients with limitations of care were lower in non-survivors compared to survivors, a finding not seen in patients with no treatment limitations.

Encouragingly, the majority of patients with treatment limitations survived their hospital stay in this cohort.
This finding is consistent with reports of improved outcomes for patients with limitations of life sustaining therapies in other recent studies. In a prospective observational study of 22 European ICUs, significantly more patients had limitations in life-sustaining therapies, while death without limitations in life-sustaining therapies occurred significantly less frequently, in 2015-2016 compared with 1999-2000 [3]. Consistent with our findings, overall survival in patients with treatment limitations was better in the 2015-6 cohort (20.4\%) compared to the 1999-2000 cohort (5.5\%). Our findings further suggest that, in the patient cohort with treatment limitations that survive to ICU discharge, the chances of survival to hospital discharge are quite favourable.

\section{Geo-economic area}

The higher SOFA sores at ICU discharge in patients from the Non-European-high income area may be explained by their shorter ICU stays [5], given that SOFA scores at day 10 post ICU admission were not different across the regions. Geo-economic location was not an independent predictor of survival in hospital post ICU discharge. The substantially higher proportion of survival patients with treatment limitations in Middle Income countries suggests these patients may be different to patients with limitations in high income countries, possibly because limitations were placed for reasons other than anticipated poor prognosis. 

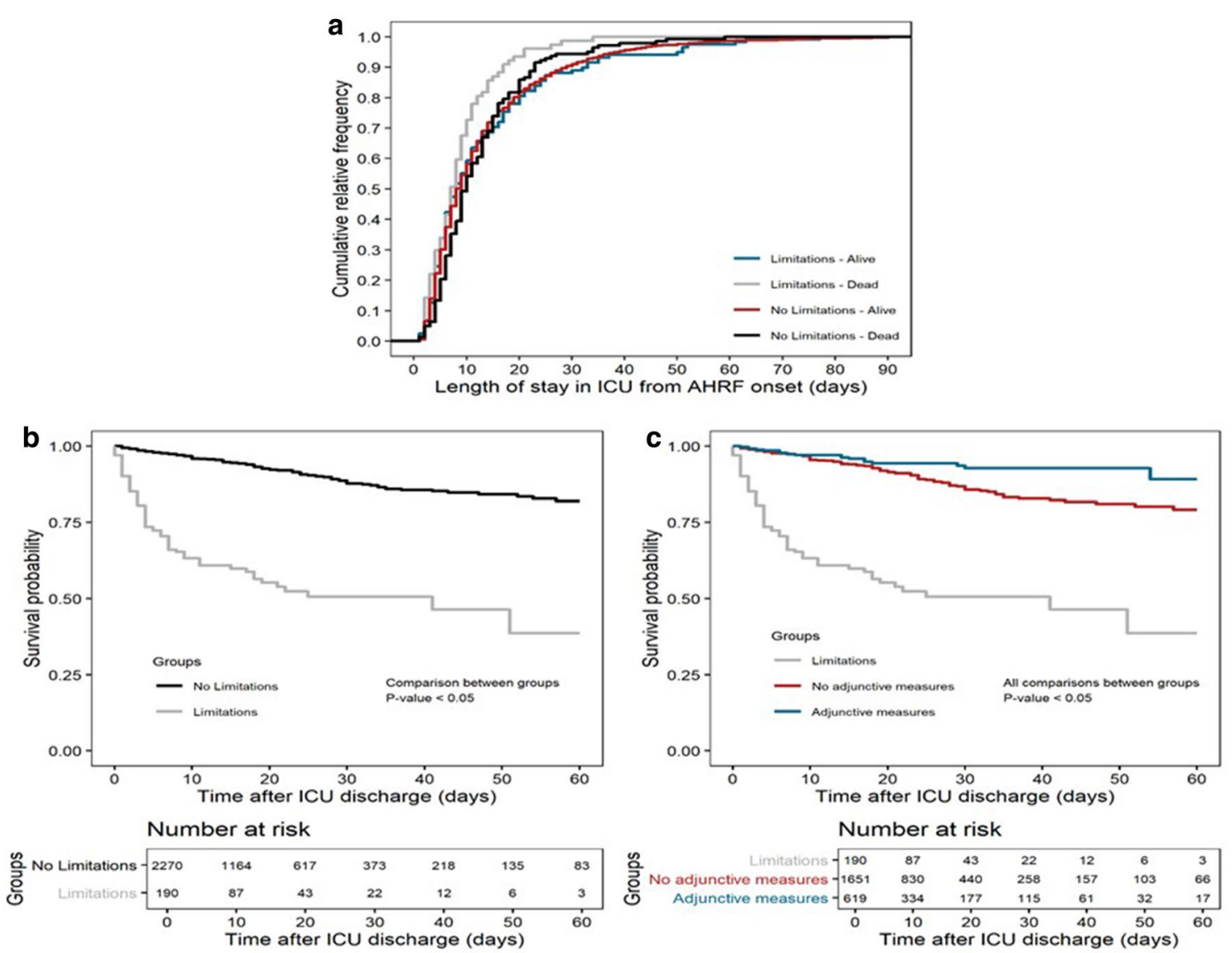

Fig. 4 Outcomes of patients that survive to hospital discharge. In a length of ICU stay was similar in patients who survived to hospital discharge and those that died, both with and without treatment limitations. In b, hospital survival rates post ICU discharge were significantly lower in patients that had treatment limitations, compared to those with no limitations. In c in patients with no limitations, survival was significantly higher in those that received adjunctive therapies

Table 6 Factors associated with hospital mortality in patients with no treatment limitations at ICU discharge

\begin{tabular}{lcc}
\hline & OR (95\% Cl) & $p$ value \\
\hline Multivariable logistic regression model 1 ( $n=1438$ on 2328) & & $<.0001$ \\
Age (years) & $1.044(1.028-1.061)$ & $<.0001$ \\
Adjusted SOFA score at last available day in ICU & $1.154(1.090-1.222)$ & 0.0031 \\
Immune-incompetence (ref. No) & $2.086(1.281-3.397)$ & 0.0383 \\
Adjunctive measures during ICU stay (ref. No) & $0.574(0.340-0.970)$ & $<.0001$ \\
Multivariable logistic regression model on patients on MV for at least 2 days (from AHRF onset) $(n=1043$ on 1656) & $1.048(1.029-1.067)$ & $<.0001$ \\
Age (years) & $1.167(1.091-1.248)$ & 0.0288 \\
Adjusted SOFA score at last available day in ICU & $1.938(1.071-3.509)$ & 0.0469 \\
Immune-incompetence (ref. No) & $0.954(0.911-0.999)$ & \\
BMI (kg/m²)
\end{tabular}

Model 1 was identified by stepwise approach using as possible predictors: baseline patients' characteristics, parameters of illness of severity at last available day in ICU use of adjunctive measures during ICU stay and ICU characteristics.

Model 2 was identified by stepwise approach using as possible predictors: baseline patients' characteristics, parameters of illness of severity and ventilator setting at last available day in ICU, use of adjunctive measures during ICU stayand ICU characteristics

Cl confidence interval, ICU intensive care unit, OR odds ratio, SOFA sequential organ failure assessment 


\section{Study limitations}

There are limitations to this study. Our study focused on identifying factors during the ICU stay, and did not examine factors following ICU discharge, that were associated with death in this population. It would likely have yielded further insights into this important area if we had collected more detailed data on the status of patients post ICU discharge, such as the Sabadell score [15]. We do not have data on any decisions made regarding limitation of life supporting measures following ICU discharge. However, our aim was to look at factors relating to the ICU stay and their impact on mortality post discharge, as this is the aspect of care under the control of the ICU team. This is not to negate the impact of events following ICU discharge on patient outcomes. In this regard, recent findings that adverse events occur commonly following ICU discharge, and can contribute to death in hospital are of particular relevance [16].

We do not have data on whether care-providers instituted treatment limitations in some patients once discharged from the ICU, nor do we have information on where patients were discharged to such as home or nursing home. We did not record details of the specific life supporting measures that were limited, or whether there were more than one decision made regarding these measures during the ICU stay.

This is a secondary and exploratory analysis of LUNG SAFE observational study and no prespecified hypotheses on mortality risk after ICU discharge were considered during study conception. As this was an exploratory study, no adjustments were made to significance levels for multiple comparison testing.

As this is an observational study, we cannot ascribe causation to factors that were associated with better outcomes including adjunctive measure use. Similar to other epidemiologic studies, we did not have access to the source data for the patients in the enrolling ICUs, and it is possible that some patients with hypoxemia, and thus ARDS, in participating centres were missed. It is important to stress, however, that ICUs were participating whether or not they identified any patient having ARDS and that the diagnosis of ARDS was not based on chart records. In addition, enrolment of patients with ARDS from participating ICUs met expectations based on their recorded 2013 admission rates, while data from lower recruiting ICUs were not different from higher enrolling ICUs, suggesting the absence of reporting biases. To ensure data quality, we instituted a robust data quality control program in which all centres were requested to verify data that appeared inconsistent or erroneous. The absence of data on other aspects of ICU management, e.g. fluid therapy, may limit the conclusions that can be drawn.

\section{Conclusions}

This is the first study to our knowledge examining factors associated with mortality post ICU discharge in patients with ARDS. Encouragingly, survival rates to hospital discharge following ICU discharge are high, with survival rates in patients with limitations of life sustaining therapy higher than expected. An important-and unexpected-finding was that even though these patients were critically ill due to ARDS, it was the non-pulmonary components of their organ dysfunction that was associated with risk of death in hospital following ICU discharge. In addition, our finding that non-survivors received less adjunctive therapies than survivors, raises important questions.

Focusing attention on this and other factors associated with death in hospital following ICU discharge may allow us to further improve outcomes in these patients.

\section{Abbreviations}

LUNG SAFE: Large observational study to UNderstand the Global impact of Severe Acute respiratory FailurE; ICUs: Intensive Care Units; ESICM: European Society of Intensive Care Medicine; AHRF: Acute hypoxemic respiratory failure; PEEP: Positive end-expiratory pressure.

\section{Supplementary Information}

The online version contains supplementary material available at https://doi. org/10.1186/s13054-021-03465-0.

Additional file 1. Supplemental Results.

\section{Acknowledgements}

The following lists comprise the members of the LUNG SAFE collaboration, and should be acknowledged as collaborating authors.

\section{Steering Committee and National Coordinators}

LUNG SAFE Steering Committee: Antonio Pesenti, John G. Laffey, Laurent Brochard, Andres Esteban, Luciano Gattinoni, Frank van Haren, Anders Larsson, Daniel F. McAuley, Marco Ranieri, Gordon Rubenfeld, B. Taylor Thompson, Hermann Wrigge, Arthur S. Slutsky.

LUNG SAFE Executive Committee: John G. Laffey, Giacomo Bellani, Tai Pham, Eddy Fan.

National coordinators for LUNG SAFE. Argentina: Fernando Rios; Australia/New Zealand: Frank van Haren; Bangladesh: Mohammad Omar Faruq; Belgium: Sottiaux T, Depuydt P; Bolivia: Fredy S Lora; Brazil: Luciano Cesar Azevedo; Canada: Eddy Fan; Chile: Guillermo Bugedo ; China: Haibo Qiu; Colombia: Marcos Gonzalez; Costa Rica: Juan Silesky; Czech Republic: Vladimir Cerny; Denmark: Jonas Nielsen; Ecuador: Manuel Jibaja; France: Tài Pham; Germany: Hermann Wrigge; Greece: Dimitrios Matamis; Guatemala: Jorge Luis Ranero; Hong Kong: Charles Gomersall; India: Pravin Amin; Iran: S.M. Hashemian; Ireland: Kevin Clarkson; Italy: Giacomo Bellani; Japan: Kiyoyasu Kurahashi; Korea: Younsuck Koh; Mexico: Asisclo Villagomez; Morocco: Amine Ali Zeggwagh; Netherlands: Leo M Heunks; Norway: Jon Henrik Laake ; Pakistan: Waqar Kashif ; Panama: Jorge Synclair; Philippines: Jose Emmanuel Palo ; Portugal: Antero do Vale Fernandes; Romania: Dorel Sandesc; Saudi Arabia: Yaasen Arabi; Serbia: Vesna Bumbasierevic; Spain: Nicolas Nin, Jose A Lorente; Sweden: Anders Larsson; Switzerland: Lise Piquilloud; Thailand: Boonsong Patjanasoontorn ; Tunisia: Fekri Abroug; United Kingdom: Daniel F McAuley, Lia McNamee; Uruguay: Javier Hurtado; USA: Ed Bajwa; Venezuela: Gabriel Démpaire; 
National Societies/Networks Endorsing LUNG SAFE. ANZICS Clinical Trials Group, Réseau Européen de Recherche en Ventilation Artificielle (ReVA Network); Irish Critical Care Trials Group; Société de Réanimation de Langue Française (SRLF); Société Française d'Anesthésie et de Réanimation (SFAR); Società Italiana Anestesia, Analgesia, Rianimazione e Terapia Intensiva (SIAARTI); The Japanese Society of Intensive Care Medicine (JSICM); Nonprofit Organization Japanese Society of Education for Physicians and Trainees in Intensive Care (JSEPTIC); UK Intensive Care Society.

Study Coordination: Guy M Francois (European Society of Intensive Care Medicine, Brussels, Belgium)

Data Revision and Management: Francesca Rabboni (University Of MilanBicocca, Monza, Italy), Fabiana Madotto (University Of Milan-Bicocca, Monza, Italy), Sara Conti (University Of Milan-Bicocca, Monza, Italy)

Site Investigators by Country: Albania: Uhc Mother Theresa (Tirana): Hektor Sula, Lordian Nunci; University Hospital Shefqet Ndroqi (Tirana): Alma Cani;

Argentina: Clinica De Especialidades (Villa Maria): Alan Zazu; Hospital Dr Julio C. Perrando (Resistencia): Christian Dellera, Carolina S Insaurralde; Sanatorio Las Lomas (San Isidro, Buenos Aires): Risso V Alejandro; Sanatorio De La Trinidad San Isidro (San Isidro): Julio Daldin, Mauricio Vinzio; Hospital Español De Mendoza (Godoy Cruz-Mendoza): Ruben O Fernandez; Hospital Del Centenario (Rosario): Luis P Cardonnet, Lisandro R Bettini; San Antonio (Gualeguay (Entre Rios)): Mariano Carboni Bisso, Emilio M Osman; Cemic (Buenos Aires): Mariano G Setten, Pablo Lovazzano; Hospital Universitrario Austral (Pilar): Javier Alvarez, Veronica Villar; Hospital Por + Salud (Pami) Dr. Cesar Milstein (Buenos Aires): Norberto C Pozo, Nicolas Grubissich; Sanatorio Anchorena (Buenos Aires): Gustavo A Plotnikow, Daniela N Vasquez; Sanatorio De La Trinidad Mitre (Buenos Aires): Santiago llutovich, Norberto Tiribelli; Hospital Luis Lagomaggiore (Mendoza): Ariel Chena, Carlos A Pellegrini; H.I.G.A San Martín (La Plata): María G Saenz, Elisa Estenssoro; Hospital Misericordia (Cordoba): Matias Brizuela, Hernan Gianinetto; Sanatorio Juncal (Temperley): Pablo E Gomez, Valeria I Cerrato; Hospital D. F. Santojanni (Buenos Aires): Marco G Bezzi, Silvina A Borello; Hospital Alejandro Posadas (Buenos Aires): Flavia A Loiacono, Adriana M Fernandez;

Australia: St. Vincents Hospital, Sydney (Darlinghurst): Serena Knowles, Claire Reynolds; St George Public Hospital (Kogarah): Deborah M Inskip, Jennene J Miller; Westmead Hospital (Westmead): Jing Kong, Christina Whitehead; Flinders Medical Centre (Bedford Park, South Australia): Shailesh Bihari; John Hunter Hospital (Newcastle): Aylin Seven, Amanda Krstevski; Canberra Hospital (Garran): Helen J Rodgers, Rebecca T Millar; Calvary Mater Newcastle (Waratah): Toni E Mckenna, Irene M Bailey; Cabrini Hospital (Melbourne): Gabrielle C Hanlon; Liverpool Hospital (Liverpool): Anders Aneman, Joan M Lynch; Coffs Harbour Health Campus (Coffs Harbour): Raman Azad, John Neal; Sir Charles Gairdner Hospital (Nedlands): Paul W Woods, Brigit L Roberts; Concord Hospital (Concord): Mark R Kol, Helen S Wong:

Austria: General Hospital Of Vienna/Medical University Of Vienna (Vienna): Katharina C Riss, Thomas Staudinger;

Belgium: Cliniques universitaires St Luc, UCL (Brussels): Xavier Wittebole, Caroline Berghe; CHU Dinant-Godinne (Yvoir): Pierre A Bulpa, Alain M Dive; AZ Sint Augustinus Veurne (Veurne): Rik Verstraete, Herve Lebbinck; Ghent University Hospital (Ghent): Pieter Depuydt, Joris Vermassen;" University Hospitals Leuven (Leuven): Philippe, Meersseman, Helga Ceunen;

Brazil: Hospital Renascentista (Pouso Alegre): Jonas I Rosa, Daniel O Beraldo; Vitoria Apart Hospital (Serra): Claudio Piras, Adenilton M Rampinelli; Hospital Das Clinicas (São Paulo): Antonio P Nassar Jr; Hospital Geral Do Grajaù (São Paulo): Sergio Mataloun, Marcelo Moock; Evangelical Hospital (Cachoeiro De Itapemirim/Espírito Santo): Marlus M Thompson, Claudio H Gonçalves-„; Hospital Moinhos De Vento (Porto Alegre): Ana Carolina P Ant ônio, Aline Ascoli; Hospital Alvorada Taguatinga (Taguatinga): Rodrigo S Biondi, Danielle C Fontenele; Complexo Hospitalar Mngabeira Tarcisio Burity (Joao Pessoa): Danielle Nobrega, Vanessa M Sales;

Brunei Darussalam: Raja Isteri Pengiran Anak Saleha (Ripas) Hospital (Bandar Seri Begawan): Dr Suresh .Shindhe, Dr Dk Maizatul Aiman B Pg Hj Ismail;

Canada: Medical-Surgical ICU of St Michael's Hospital (Toronto): John Laffey, Francois Beloncle; St. Josephs Health Centre (Toronto): Kyle G Davies, Rob Cirone; Sunnybrook Health Sciences Center (Toronto): Venika Manoharan, Mehvish Ismail; Toronto Western Hospital (Toronto): Ewan C Goligher, Mandeep Jassal; Medical Surgical ICU of the Toronto General Hospital (Toronto): Niall D. Ferguson, Erin Nishikawa, Areej Javeed; Cardiovascular ICU of St Michael's Hospital (Toronto): Gerard Curley, Nuttapol Rittayamai ; Cardiovascular ICU of the Toronto General Hospital (Toronto): Matteo Parotto, Mount
Sinai Hospital (Toronto): Sangeeta Mehta, Jenny Knoll ; Trauma-Neuro ICU of St Michael's Hospital (Toronto): Antoine Pronovost, Sergio Canestrini

Chile: Hospital Clínico Pontificia Universidad Católica De Chile (Santiago): Alejandro R Bruhn, Patricio H Garcia; Hospital Militar De Santiago (Santiago): Felipe A Aliaga, Pamela A Farías; Clinica Davila (Santiago): Jacob S Yumha; Hospital Guillermo Grant Benavente (Concepcion): Claudia A Ortiz, Javier E Salas; Clinica Las Lilas (Santiago): Alejandro A Saez, Luis D Vega; Hospital Naval Almirante Nef (Viña Del Mar): Eduardo F Labarca, Felipe T Martinez; Hospital Luis Tisné Brousse (Penanolen): Nicolás G Carreño, Pilar Lora:

China: The Second Affiliated Hospital Of Harbin Medical University (Harbin): Haitao Liu; Nanjing Zhong-Da Hospital, Southeast University (Nanjing): Haibo Qiu, Ling Liu; The First AffiliatedHospital Of Anhui Medical University (Hefei): Rui/Tang, Xiaoming Luo; Peking University People's Hospital (Beijing): Youzhong An, Huiying Zhao; Fourth Affiliated Hospital Of Harbin Medical University (Harbin): Yan—Gao, Zhe-Zhai; Nanjing Jiangbei Peoples Hospital Affiliated To Medical School Of Southeast University (Nanjing): Zheng L Ye, Wei Wang; The First Affiliated Hospital Of Dalian Medical Unvercity (Dalian): Wenwen Li, Qingdong Li; Subei Peoples Hospital Of Jiangsu Province (Yanghzou): Ruiqiang Zheng; Jinling Hospital (Nanjing): Wenkui Yu, Juanhong Shen; Urumqi General Hospital (Urumqi): XinyuLi; Intensive Care Unit, First Affiliated Hospital Of Wanna Medical College, Yijishan Hospital, (Wuhu): Tao Yu, Weihua Lu; Sichuan Provincial Peoples Hospital (Chengdu): Ya Q Wu, Xiao B Huang; Hainan Province Peoples Hospital (Haikou): Zhenyang He; Peoples Hospital Of Jiangxi Province (Nanchang): Yuanhua Lu; Qilu Hospital Of Shandong University (Jinan): Hui Han, Fan Zhang; Zhejiang Provincial Peoples Hospital (Hangzhou): Renhua Sun; The First Affiliated Hospital Of Bengbu Medical College (Bengbu, Anhui): Hua X Wang, Shu H Qin; Nanjing Municipal Government Hospital (Nanjing): Bao H Zhu, Jun Zhao; The First Hospital Of Lanzhou University (Lanzhou): Jian/Liu, Bin/Li; The First Affiliated Hospital Of Chongqing University Of Medical Science (Chongqing): Jing L Liu, Fa C Zhou; Xuzhou Central Hospital, Jiangsu Province, China (Xuzhou): Qiong J Li, Xing Y Zhang; The First Peoples Hospital Of Foshan (Foshan): Zhou Li-Xin, Qiang Xin-Hua; The First Affiliated Hospital Of Guangxi Medical University (Nanning): Liangyan Jiang; Renji Hospital, Shanghai Jiao Tong University School Of Medicine (Shanghai): Yuan N Gao, Xian Y Zhao; First Hospital Of Shanxi Medical University (Taiyuan): Yuan Y Li, Xiao L Li; Shandong Provincial Hospital (Jinan): Chunting Wang, Qingchun Yao; Fujian Provincial Hospital (Fuzhou): Rongguo Yu, Kai Chen; Henan Provincial People's Hospital (Zhengzhou): Huanzhang Shao, Bingyu Qin; The Second Affiliated Hospital Of Kunming Medical University (Kunming City): Qing Q Huang, Wei H Zhu; Xiangya Hospital, Central South University (Changsha): Ai Y Hang, Ma X Hua; The First Affiliated Hospital Of Guangzhou Medical University (Guangzhou): Yimin Li, Yonghao Xu; Peoples Hospital of Hebei Province (Shijiazhuang): Yu D Di, Long L Ling; Guangdong General Hospital (Guangzhou): Tie H Qin, Shou H Wang; Beijing Tongren Hospital (Beijing): Junping Qin; Jiangsu Province Hospital (Nanjing): Yi Han, Suming Zhou; COLOMBIA: Fundación Valle Del Lili (Cali): Monica P Vargas;

Costa Rica: Hospital San Juan De Dios (): Juan I Silesky Jimenez, Manuel A González Rojas; Hospital San Juan De Dios (San José): Jaime E Solis-Quesada, Christian M Ramirez-Alfaro;

Czech Republic: University Hospital Of Ostrava (Ostrava): Jan Máca, Peter Sklienka;

Denmark: Aarhus Universitetshospital (Aarhus N): Jakob Gjedsted, Aage Christiansen; Rigshopitalet: Jonas Nielsen;

Ecuador: Hospital Militar (Quito): Boris G Villamagua, Miguel Llano;

France: Clinique du Millénaire (Montpellier): Philippe Burtin, Gautier Buzancais; Centre Hospitalier (Roanne): Pascal Beuret, Nicolas Pelletier; CHU d'Angers (Angers): Satar Mortaza, Alain Mercat; Hôpital Marc Jacquet (Melun): Jonathan Chelly, Sébastien Jochmans; CHU de Caen (Caen): Nicolas Terzi, Cédric Daubin; Henri Mondor Hospital (Créteil): Guillaume Carteaux, Nicolas de Prost; Cochin Hospital (Paris): Jean-Daniel Chiche, Fabrice Daviaud; CHU Tenon (Paris): Tài Pham, Muriel Fartoukh; CH Mulhouse-Emile Muller (Mulhouse): Guillaume Barberet, Jerome Biehler; Archet 1 University Hospital (Nice): Jean Dellamonica, Denis Doyen; Hopital Sainte Musse (Toulon): Jean-Michel Arnal, Anais Briquet; Hopital Nord-Réanimation des Détresses Respiratoires et Infections Sévères (Marseille): Fanny Klasen, Laurent Papazian; HEGP (Paris): Arnaud Follin; Louis Mourier Hospital (Colombes): Damien Roux, Jonathan Messika; Centre Hospitalier de Dax (Dax): Evangelos Kalaitzis; Réanimation Médicale, GH Pitié-Salpêtrière (Paris): Laurence Dangers, Alain Combes; Ap-Hp Ambroise Paré (Boulogne-Billancourt): Siu-Ming Au; University Hospital Rouen (Rouen): Gaetan Béduneau, Dorothée Carpentier; CHU Amiens (AmiensSalouel): Elie H Zogheib, Herve Dupont; Centre Hospitalier Intercommunal 
Robert Ballanger (Aulnay Sous Bois): Sylvie Ricome, Francesco L Santoli; Centre Hospitalier René Dubos (Pontoise): Sebastien L Besset; CHI Portes de I'Oise (Beaumont Sur Oise): Philippe Michel, Bruno Gelée; Archet 2 University Hospital (Nice): Pierre-Eric Danin, Bernard Goubaux; Centre Hospitalier Pierre Oudot (Bourgoin Jallieu): Philippe J Crova, Nga T Phan; CH Dunkerque (Dunkerque): Frantz Berkelmans; Centre Hospitalier de Belfort Montbéliard (Belfort): Julio C Badie, Romain Tapponnier; Centre Hospitalier Emile Muller (Mulhouse): Josette Gally, Samy Khebbeb; Hôpital de Hautepierre-Hôpitaux Universitaires de Strasbourg (Strasbourg): Jean-Etienne Herbrecht, Francis Schneider; Centre Hospitalier de Dieppe (Dieppe): Pierre-Louis M Declercq, Jean-Philippe Rigaud; Bicêtre (Le Kremin-Bicetre): Jacques Duranteau, Anatole Harrois; CHU Gabriel Montpied (Clermont-Ferrand): Russell Chabanne, Julien Marin; CHU Estaing (Clermont-Ferrand): Jean-Michel Constantin, Sandrine Thibault; CHI Eure-Seine Evreux (Evreux): Mohammed Ghazi, Messabi Boukhazna; Centre Hospitalier de Châlons en Champagne (Châlons en Champagne): Salem Ould Zein; $\mathrm{CH}$ Beauvais (Beauvais): Jack R Richecoeur, Daniele M Combaux; Centre Hospitalier Le Mans (Le Mans): Fabien Grelon, Charlene Le Moal; Hôpital Fleyriat (Bourg en Bresse): Elise P Sauvadet, Adrien Robine; Hôpital Saint Louis (Paris): Virginie Lemiale, Danielle Reuter; Pneumologie et Réanimation Médicale, Hôpital Pitié-Salpêtrière (Paris): Martin Dres, Alexandre Demoule; Centre Hospitalier Gonesse (Gonesse): Dany Goldgran-Toledano; Hôpital Croix Rousse (Lyon): Loredana Baboi, Claude Guérin;

Germany: St. Nikolaus-Stiftshospital (Andernach): Ralph Lohner; Fachkrankenhaus Coswig Gmbh (Coswig):Jens Kraßler, Susanne Schäfer; University Hospital Frankfurt (Frankfurt am Main): Kai D Zacharowski, Patrick Meybohm; Department of Anaesthesia \& Intensive Care Medicine, University Hospital of Leipzig (Leipzig): Andreas W Reske, Philipp Simon; Asklepios Klinik Langen (Langen): Hans-Bernd F Hopf, Michael Schuetz; Städtisches Krankenhaus Heinsberg (Heinsberg): Thomas Baltus;

Greece: Hippokrateion General Hospital Of Athens (Athens): Metaxia N Papanikolaou, Theonymfi G Papavasilopoulou; Gh Ahepa (Thessaloniki): Giannis A Zacharas, Vasilis Ourailogloy; Hippokration General Hospital of Thessaloniki (Thessaloniki): Eleni K Mouloudi, Eleni V Massa; Hospital General of Kavala (Kavala): Eva O Nagy, Electra E Stamou; Papageorgiou General Hospital (Thessaloniki): Ellada V Kiourtzieva, Marina A Oikonomou;

Guatemala: Hospital General De Enfermedades, Instituto Guatemalteco De Seguridad Social (Ciudad De Guatemala): Luis E Avila; Centro Médico Militar (Guatemala): Cesar A Cortez, Johanna E Citalán;

India: Deenanath Mangeshkar Hospital And Research Center (Pune): Sameer A Jog, Safal D Sable; Care Institute Of Medical Sciences (CIMS) Hospital (Ahmedabad): Bhagyesh Shah; Sanjay Gandhi Postgraduate Institute Of Medical Sciences (SGPGIMS) (Lucknow): Mohan Gurjar, Arvind K Baronia; Rajasthan Hospital (Ahmedabad): Mohammedfaruk Memon; National Institute Of Mental Health And Neuro Sciences (NIMHANS) (Bangalore): Radhakrishnan Muthuchellappan, Venkatapura J Ramesh; Anaesthesiology Unit of the Kasturba Medical College \& Dept of Respiratory Therapy, SHOAS, Manipal University (Manipal): Anitha Shenoy, Ramesh Unnikrishnan; Sanjeevan Hospital (Pune): Subhal B Dixit, Rachana V Rhayakar; Apollo Hospitals (Chennai): Nagarajan Ramakrishnan, Vallish K Bhardwaj; Medicine Unit of the Kasturba Medical College \& Dept of Respiratory Therapy, SHOAS, Manipal University (Manipal): Heera L Mahto, Sudha V Sagar; G Kuppuswamy Naidu Memorial Hospital (Coimbatore): Vijayanand Palaniswamy, Deeban Ganesan;

Iran: NRITLD/Masih Daneshvari (Tehran): Seyed Mohammadreza Hashemian, Hamidreza Jamaati ; Milad Hospital (Tehran): Farshad Heidari

Ireland: St Vincent's University Hospital (Dublin): Edel A Meaney, Alistair Nichol; Mercy University Hospital (Cork): Karl M Knapman, Donall O'Croinin ; Cork University Hospital (Cork): Eimhin S Dunne, Dorothy M Breen; Galway University Hospital (Galway): Kevin P Clarkson, Rola F Jaafar; Beaumont Hospital (Dublin): Rory Dwyer, Fahd Amir; Mater Misericordiae University Hospital (Dublin): Olaitan O Ajetunmobi, Aogan C O'Muircheartaigh; Tallaght Hospital (Dublin): Colin S Black, Nuala Treanor; Saint James's Hospital (Dublin): Daniel V Collins, Wahid Altaf;

Italy: Santa Maria delle Croci Hospital (Ravenna): Gianluca Zani, Maurizio Fusari; Arcispedale Sant'Anna Ferrara. (Ferrara): Savino Spadaro, Carlo A Volta; Ospedale Profili (Fabriano) (An): Romano Graziani, Barbara Brunettini; Umberto I Nocera Inferiore (Nocera Inferiore Salerno): Salvatore Palmese; Azienda Ospedaliera San Paolo_Polo Universitario- Università degli Studi di Milano (Milan): Paolo Formenti, Michele Umbrello; Sant'Anna (San Fermo Della Battaglia (Co)): Andrea Lombardo; Spedali Civili Brescia (Brescia): Elisabetta Pecci, Marco Botteri; Fondazione Irccs Ca Granda, Ospedale Maggiore Policlinico (Milan): Monica Savioli, Alessandro Protti; University Campus Bio-Medico of Rome (Rome):
Alessia Mattei, Lorenzo Schiavoni; Azienda Ospedaliera "Mellino Mellini" (Chiari (Bs)): Andrea Tinnirello, Manuel Todeschini; Policlinico P. Giaccone, University of Palermo (Palermo): Antonino Giarratano, Andrea Cortegiani; Niguarda Cà Granda Hospital (Milan): Sara Sher, Anna Rossi; A.Gemelli University Hospital (Rome): Massimo M Antonelli, Luca M Montini; Ospedale "Sandro Pertini" (Rome): Paolo Casalena, Sergio Scafetti; ISMeTT IRCCS UPMC (Palermo): Giovanna Panarello, Giovanna Occhipinti; Ospedale San Gerardo (Monza): Nicolò Patroniti, Matteo Pozzi; Santa Maria Della Scaletta (Imola): Roberto R Biscione, Michela M Poli; Humanitas Research Hospital (Rozzano): Ferdinando Raimondi, Daniela Albiero;Ospedale Desio—Ao Desio-Vimercate (Desio): Giulia Crapelli, Eduardo Beck; Pinetagrande Private Hospital (Castelvolturno): Vincenzo Pota, Vincenzo Schiavone; Irccs San Martino Ist (Genova): Alexandre Molin, Fabio Tarantino; Ospedale San Raffaele (Milano): Giacomo Monti, Elena Frati; Ospedali Riuniti Di Foggia (Foggia): Lucia Mirabella, Gilda Cinnella; Azienda Ospedaliera Luigi Sacco-Polo Universitario (Milano): Tommaso Fossali, Riccardo Colombo; A.O.U. Città della Salute e della Scienza di Torino (Turin): Pierpaolo Terragni Ilaria Pattarino; Università degli Studi di Pavia-Fondazione IRCCS Policlinico San Matteo (Pavia): Francesco Mojoli, Antonio Braschi; Ao Ospedale Civile Legnano (Legnano): Erika E Borotto; Arnas Ospedale Civico Di Cristina Benfratelli (Palermo): Andrea N Cracchiolo, Daniela M Palma; Azienda Ospedaliera Della Provincia Di Lecco—Ospedale "A. Manzoni" (Lecco): Francesco Raponi, Giuseppe Foti; A.O. Provincia Di Lecco-Ospedale Alessandro Manzoni (Lecco): Ettore R Vascotto, Andrea Coppadoro; Cliniche Universitarie Sassari (Sassari): Luca Brazzi, Leda Floris; IRCCS Policlinico San Matteo (Pavia): Giorgio A lotti, Aaron Venti;

Japan: Yokohama City University Hospital (Yokohama): Osamu Yamaguchi, Shunsuke Takagi; Toyooka Hospital (Toyooka City,Hyogo Prefecture): Hiroki N Maeyama; Chiba University Hospital (Chiba City): Eizo Watanabe, Yoshihiro Yamaji; Okayma University Hospital (Okayama): Kazuyoshi Shimizu, Kyoko Shiozaki; Japanese Foundation for Cancer Research, Cancer Institute Hospital, Department Of Emergency Medicine And Critical Care (Tokyo): Satoru Futami; Ibaraki Prefectural Central Hospital (Kasama): Sekine Ryosuke; Tohoku University Hospital (Sendai-Shi): Koji Saito, Yoshinobu Kameyama; Tokyo Medical University Hachioji Medical Center (Hachioji, Tokyo): Keiko Ueno; Tokushima University Hospital (Tokushima): Masayo . Izawa, Nao Okuda; Maebashi Red Cross Hospital (Gunma Maebashi): Hiroyuki Suzuki, Tomofumi Harasawa; Urasoe General Hospital (Urasoe): Michitaka Nasu, Tadaaki Takada; Ohta General Hospital Foundation Ohta Nishinouchi Hospital (Fukushima): Fumihito Ito; Jichi Medical University Hospital (Shimotsuke): Shin—Nunomiya, Kansuke—Koyama; Mito Kyodo General Hospital, Tsukuba University Hospital Mito Medical Center (Mito): Toshikazu Abe; Sendai City Hospital (Sendai): Kohkichi Andoh, Kohei Kusumoto; Ja Hiroshima General Hospital (Hatsukaichi City, Hiroshima): Akira Hirata, Akihiro Takaba; Yokohama Rosai Hospital (Yokohama): Hiroyasu Kimura; Nagasaki University Hospital (Nagasaki): Shuhei Matsumoto, Ushio Higashijima; Niigata University Medical \& Dental Hospital (Niigata): Hiroyuki Honda, Nobumasa Aoki; Mie University Hospital (Tsu, Mie): Hiroshi Imai; Yamaguchi University Hospital (Ube, Yamaguchi): Yasuaki Ogino, Ichiko Mizuguchi; Saiseikai Kumamoto Hospital (Kumamoto City): Kazuya Ichikado; Shinshu University School Of Medecine (Matsumoto City): Kenichi Nitta, Katsunori Mochizuki; Kuki General Hospital (Kuki): Tomoaki Hashida; Kyoto Medical Center (Kyoto): Hiroyuki Tanaka ; Fujita Health University (Toyoake): Tomoyuki Nakamura, Daisuke Niimi; Rakwakai Marutamachi Hospital (Kyoto): Takeshi Ueda; Osaka University Hospital (Suita City, Osaka Prefecture): Yozo Kashiwa, Akinori Uchiyama;

Latvia: Paul Stradins Clinical University Hospital (Riga): Olegs Sabelnikovs , Peteris Oss;

Lebanon: Kortbawi Hospital (Jounieh): Youssef Haddad;

Malaysia: Hospital Kapit (Kapit): Kong Y Liew;

Mexico: Instituto Nacional De Cancerología, México (Mexico City): Silvio A Ñamendys-Silva, Yves D Jarquin-Badiola; Hospital De Especialidades "Antonio Fraga Mouret" Centro Medico Nacional La Raza IMSS (Mexico City): Luis A Sanchez-Hurtado, Saira S Gomez-Flores; Hospital Regional $1^{\circ}$ De Octubre (Mexico City): Maria C Marin, Asisclo J Villagomez; Hospital General Dr Manuel Gea Gonzalez (Mexico City): Jordana S Lemus, Jonathan M Fierro; Hospital General De Zona No. 1 Instituto Mexicano Del Seguro Social Tepic Nayarit (Tepic): Mavy Ramirez Cervantes, Francisco Javier Flores Mejia; Centro Medico Dalinde (Mexico D.F.): Dulce Dector, Dulce M Dector; Opd Hospital Civil De Guadalajara Hospital Juan I Menchaca (Guadalajara): Daniel R Gonzalez, Claudia R Estrella; Hospital Regional De Ciudad Madero Pemex (Ciudad Madero): Jorge R Sanchez-Medina, Alvaro Ramirez-Gutierrez; Centro Médico ABC 
(Mexico D.F.): Fernando G George, Janet S Aguirre; Hospital Juarez De Mexico (Mexico City): Juan A Buensuseso, Manuel Poblano;

Morocco: Mohammed V University, University Teaching Ibn Sina Hospital (Rabat): Tarek Dendane, Amine Ali Zeggwagh; Hopital Militaire D'Instruction Mohammed V (Rabat): Hicham Balkhi; Errazi (Marrakech): Mina Elkhayari, Nacer Samkaoui; University Teaching Hospital Ibn Rushd (Casablanca): Hanane Ezzouine, Abdellatif Benslama; Hôpital des Spécialités de Rabat (HSR) (Rabat): Mourad Amor, Wajdi Maazouzi;

Netherlands: Tjongerschans (Heerenveen): Nedim Cimic, Oliver Beck; Cwz (Nijmegen): Monique M Bruns, Jeroen A Schouten; Rijnstate Hospital (Arnhem): Myra—Rinia, Monique Raaijmakers; Radboud Umc (Nijmegen): Leo M Heunks, Hellen M Van Wezel; Maastricht University Medical Centre (Maastricht): Serge J Heines, Ulrich Strauch; Catharinaziekenhuis (Eindhoven): Marc P Buise; Academic Medical Center (Amsterdam): Fabienne D Simonis, Marcus J Schultz;

New Zealand: Tauranga Hospital (Tauranga): Jennifer C Goodson, Troy S Browne; Wellington Hospital (Wellington): Leanlove Navarra, Anna Hunt; Dunedin Hospital (Dunedin): Robyn A Hutchison, Mathew B Bailey; Auckland City Hospital (Auckland): Lynette Newby, Colin Mcarthur; Whangarei Base Hospital (Whangarei): Michael Kalkoff, Alex Mcleod; North Shore Hospital (Auckland): Jonathan Casement, Danielle J Hacking;

Norway: Ålesund Hospital (Ålesund): Finn H Andersen, Merete S Dolva; Oslo University Hospital—Rikshospitalet Medical Centre (Oslo): Jon H Laake, Andreas Barratt-Due; Stavanger University Hospital (Stavanger): Kim Andre L Noremark, Eldar Søreide; Haukeland University Hospital (Bergen): Brit Å Sjøbø, Anne B Guttormsen;

Peru: Hospital Nacional Edgardo Rebagliati Martins (Lima): Hector H Leon Yoshido; Clínica Ricardo Palma (Lima): Ronald Zumaran Aguilar, Fredy A Montes Oscanoa;

Philippines: The Medical City (Pasig): Alain U Alisasis, Joanne B Robles; Chong Hua Hospital (Cebu): Rossini Abbie B Pasanting-Lim, Beatriz C Tan;

Poland: Warsaw University Hospital (Warsaw): Pawel Andruszkiewicz, Karina Jakubowska;

Portugal: Centro Hospitalar Da Cova Da Beira (Covilhã): Cristina M Coxo; Hospital Santa Maria, Chln (Lisboa): António M Alvarez, Bruno S Oliveira; Centro Hospitalar Trás-Os-Montes E Alto Douro—Hospital De S.Pedro -Vila Real (Vila Real): Gustavo M Montanha, Nelson C Barros; Hospital Beatriz Ângelo (Loures): Carlos S Pereira, António M Messias; Hospital De Santa Maria (Lisboa): Jorge M Monteiro; Centro Hospitalar Médio Tejo—Hospital De Abrantes (Abrantes): Ana M Araujo, Nuno T Catorze; Instituto Português De Oncologia De Lisboa (Lisboa): Susan M Marum, Maria J Bouw; Hospital Garcia De Orta (Almada): Rui M Gomes, Vania A Brito; Centro Hospitalar Do Algarve (Faro): Silvia Castro, Joana M Estilita; Hpp Hospital De Cascais (Alcabideche): Filipa M Barros; Hospital Prof. Doutor Fernando Fonseca Epe (Amadora): Isabel M Serra, Aurelia M Martinho:

Romania: Fundeni Clinical Institute (Bucharest): Dana RTomescu, Alexandra Marcu; Emergency Clinical County Hospital Timisoara (Timisoara): Ovidiu H Bedreag, Marius Papurica; Elias University Emergency Hospital (Bucharest): Dan E Corneci, Silvius loan Negoita;

Russian Federation: University Hospital (Kemerovo): Evgeny Grigoriev ;Krasnoyarsk Regional Hospital, Krasnoyarsk State Medical University (Krasnoyarsk): Alexey I Gritsan, Andrey A Gazenkampf;

Saudi Arabia: GICU of PSMMC (Riyadh): Ghaleb Almekhlafi, Mohamad M Albarrak; SICU of PSMMC (Riyadh): Ghanem M Mustafa; King Faisal Hospital And Research Center (Riyadh): Khalid A Maghrabi, Nawal Salahuddin; King Fahad Hospital (Baha): Tharwat M Aisa; King Abdulaziz Medical City (Riyadh): Ahmed S Al Jabbary, Edgardo Tabhan; King Abdulaziz Medical City (Riyadh): Yaseen M Arabi; King Abdulaziz Medical City (Riyadh): Yaseen M Arabi, Olivia A Trinidad; King Abdulaziz Medical City (Riyadh): Hasan M Al Dorzi, Edgardo E Tabhan;

South Africa: Charlotte Maxeke Johannesburg Academic Hospital (Johannesburg): Stefan Bolon, Oliver Smith;

Spain: Hospital Sant Pau (Barcelona): Jordi Mancebo, Hernan AguirreBermeo; Hospital Universitari Bellvitge (L Hospitalet De Llobregat (Barcelona)): Juan C Lopez-Delgado, Francisco Esteve; Hospital Son Llatzer (Palma De Mallorca): Gemma Rialp, Catalina Forteza; Sabadell Hospital, CIBER Enfermedades Respiratorias (Sabadell): Candelaria De Haro, Antonio Artigas; Hospital Universitario Central De Asturias (Oviedo): Guillermo M Albaiceta, Sara De Cima-Iglesias; Complejo Hospitalario Universitario A Coruña (A Coruña): Leticia Seoane-Quiroga, Alexandra Ceniceros-Barros; Hospital Universitario Miguel Servet (Zaragoza): Antonio L Ruiz-Aguilar, Luis M Claraco-Vega; Morales Meseguer University Hospital (Murcia): Juan Alfonso Soler, Maria del Carmen
Lorente; Hospital Universitario del Henares(Coslada): Cecilia Hermosa, Federico Gordo; Complejo Asistencial De Palencia. Hospital Rio Carrión (Palencia): Miryam —Prieto-González, Juan B López-Messa; Fundación Jiménez Díaz (Madrid): Manuel P Perez, Cesar P Perez; Hospital Clínico Universitario Lozano Blesa (Zaragoza): Raquel Montoiro Allue; Hospital Verge de la Cinta (Tortosa): Ferran Roche-Campo, Marcos Ibañez-Santacruz; Hospital Universitario 12 De Octubre (Madrid): Susana_Temprano; Hospital Universitario Príncipe De Asturias (Alcalá De Henares, Madrid): Maria C Pintado, Raul De Pablo; Hospital Universitari Germans Trias I Pujol (Badalona): Pilar Ricart Aroa Gómez; Hospital Universitario Arnau De Vilanova De Lleida (Lleida): Silvia Rodriguez Ruiz, Silvia Iglesias Moles; Cst Terrassa (Barcelona): Ma Teresa Jurado, Alfons Arizmendi; Hospital Universitari Mútua Terrassa (Terrassa): Enrique A Piacentini; Hospital Universitario De Móstoles (Mostoles): Nieves Franco, Teresa Honrubia; Complejo Asistencial De Salamanca (Salamanca): Meisy Perez Cheng, Elena Perez Losada; Hospital General Universitario De Ciudad Real (Ciudad Real): Javier-Blanco, Luis J Yuste; Torrecardenas (Almeria): Cecilia Carbayo-Gorriz, Francisca G Cazorla-Barranquero; Hospital Universitario Donostia (San Sebastian): Javier G Alonso, Rosa S Alda; Hospital Universitario De Torrejón (Madrid): Ángela Algaba, Gonzalo Navarro; Hospital Universitario De La Princesa (Madrid): Enrique Cereijo, Esther Diaz-Rodriguez; Hospital Universitario Lucus Augusti (Lugo): Diego Pastor Marcos, Laura Alvarez Montero; Hospital Universitario Santa Lucia (Cartagena): Luis Herrera Para, Roberto Jimenez Sanchez; Hospital Universitario Severo Ochoa, Leganes (Madrid): Miguel Angel Blasco Navalpotro, Ricardo Diaz Abad; University Hospital Of Ntra. Sra. De Candelaria (Santa Cruz De Tenerife): Raquel Montiel Gonz á lez, D á cil Parrilla Toribio; Hospital Universitario Marques De Valdecilla (Santander): Alejandro G Castro, Maria Jose D Artiga; Hospital Infanta Cristina (Parla, Madrid): Oscar Penuelas ; Hospital General De Catalunya (Sant Cugat Del Valles): Tomas P Roser, Moreno F Olga; San Pedro De Alcántara (Cáceres): Elena Gallego Curto, Rocío Manzano Sánchez; Sant Joan De Reus (Reus): Vallverdu P Imma, Garcia M Elisabet; Hospital Joan XXIII (Tarragona): Laura Claverias, Monica Magret; Hospital Universitario De Getafe (Madrid): Ana M Pellicer, Lucia L Rodriguez; Hospital Universitario Río Hortega (Valladolid): Jesús Sánchez-Ballesteros, Ángela González-Salamanca; Hospital Arquitecto Marcide (Ferrol,La Coruña): Antonio G Jimenez, Francisco P Huerta; Hospital General Universitario Gregorio Marañón (Madrid): Juan Carlos J Sotillo Diaz, Esther Bermejo Lopez;Hospital General De Segovia (Segovia): David D Llinares Moya, Alec A Tallet Alfonso; Hospital General Universitario Reina Sofia (Murcia): Palazon Sanchez Eugenio Luis, Palazon Sanchez Cesar; Complejo Hospitalario Universitario De Albacete (Albacete): Sánchez I Rafael, Corcoles G Virgilio; Hospital Infanta Elena (Valdemoro): Noelia N Recio;

Sweden: Sahlgrenska University Hospital (Gothenburg): Richard O Adamsson, Christian C Rylander; Karolinska University Hospital (Stockholm): Bernhard Holzgraefe, Lars M Broman; Akademiska Sjukhuset Uppsala (Uppsala): Joanna Wessbergh, Linnea Persson; Vrinnevisjukhuset (Norrköping): Fredrik Schiöler, Hans Kedelv; Linkoping University Hospital (Linköping): Anna Oscarsson Tibblin, Henrik Appelberg; Skellefteå Lasarett (Skellefteå): Lars Hedlund, Johan Helleberg; Karolinska University Hospital Solna (Stockholm): Karin E Eriksson, Rita Glietsch; Umeå University Hospital (Umeå): Niklas Larsson, Ingela Nygren; Danderyd Hospital (Stockholm): Silvia L Nunes, Anna-Karin Morin; Lund University Hospital (Lund): Thomas Kander, Anne Adolfsson;

Switzerland: Chuv (Centre Hospitalier Universitaire Vaudois) (Lausanne): Lise Piquilloud; Hôpital neuchâtelois_La Chaux-De-Fonds (La Chaux-DeFonds): Hervé O. Zender, Corinne Leemann-Refondini;

Tunisia: Hopital Taher Sfar Mahdia (Mahdia): Souheil Elatrous; University Hospital Farhat Hached Sousse (Sousse): Slaheddine Bouchoucha, Imed Chouchene; CHU F.Bourguiba (Monastir): Islem Ouanes; Mongi Slim University Hospital, La Marsa (La Marsa): Asma Ben Souissi, Salma Kamoun;

Turkey: Cerrahpasa Medical Faculty Emergency Intensive Care Unit (Istanbul): Oktay Demirkiran; Cerrahpasa Medical Faculty Sadi Sun Intensive Care Unit (Istanbul) : Mustafa Aker, Emre Erbabacan; Uludag University Medical Faculty (Bursa): Ilkay Ceylan, Nermin Kelebek Girgin; Ankara University Faculty of Medicine, Reanimation 3nd level ICU (Ankara): Menekse Ozcelik, Necmettin Ünal; Ankara University Faculty of Medicine, 2nd level ICU-postoperative ICU (Ankara): Basak Ceyda Meco; Istanbul Kartal Egitim Ve Arastirma Hastanesi (Istanbul): Onat O Akyol, Suleyman S Derman;

United Kingdom: Papworth Hospital (Cambridge): Barry Kennedy, Ken Parhar; Royal Glamorgan Hospital (Llantrisant): Latha Srinivasa; Royal Victoria Hospital-Belfast (Belfast): Lia McNamee, Danny McAuley; Jack Steinberg ICU of the King's College (London): Phil Hopkins, Clare Mellis; Frank Stansil ICU of the King's College Hospital (London): Vivek Kakar; ;Liver ICU of the King's College 
(London): Dan Hadfield; Christine Brown ICU of the King's College (London): Andre Vercueil; West Suffolk Hospital (Bury St Edmunds): Kaushik Bhowmick, Sally K Humphreys; Craigavon Area Hospital (Portadown): Andrew Ferguson, Raymond Mckee; Barts Health NHS Trust, Whipps Cross Hospital (Leytonstone): Ashok S Raj, Danielle A Fawkes; Kettering General Hospital, Foundation NHS Trust (Northamptonshire): Philip Watt, Linda Twohey; Barnet General Hospital (Barnet): Rajeev R JhaMatthew Thomas, Alex Morton, Varsha Kadaba; Rotherham General Hospital (Rotherham): Mark J Smith, Anil P Hormis; City Hospital, (Birmingham): Santhana G Kannan, Miriam Namih; Poole Hospital NHS Foundation Trust (Poole): Henrik Reschreiter, Julie Camsooksai; Weston General Hospital (Weston-Super-Mare): Alek Kumar, Szabolcs Rugonfalvi; Antrim Area Hospital (Antrim): Christopher Nutt, Orla Oneill; Aintree University Hospital (Liverpool): Colette Seasman, Ged Dempsey; Northern General Hospital (Sheffield): Christopher J Scott, Helen E Ellis; John Radcliffe Hospital (Oxford): Stuart Mckechnie, Paula J Hutton; St Georges Hospital (London): Nora N Di Tomasso, Michela N Vitale; Hillingdon Hospital (Uxbridge): Ruth 0 Griffin, Michael N Dean; The Royal Bournemouth \& Christchurch NHS Foundation Trust (Bournemouth, Dorset): Julius H Cranshaw, Emma L Willett; Guys And St Thomas NHS Foundation Trust (London): Nicholas loannou, Gstt Severe Respiratory Failure Service ; Whittington Hospital (London): Sarah Gillis; Wexham Park Hospital (Slough): Peter Csabi; Western General Hospital (Edinburgh): Rosaleen Macfadyen, Heidi Dawson; Royal Preston Hospital (Preston): Pieter D Preez, Alexandra J Williams; Brighton And Sussex University Hospitals NHS Trust (Brighton): Owen Boyd, Laura Ortiz-Ruiz De Gordoa; East And North Herts NHS Trust (Stevenage): Jon Bramall, Sophie Symmonds; Barnsley Hospital (Barnsley): Simon K Chau, Tim Wenham; Prince Charles Hospital (Merthyr Tydfil): Tamas Szakmany, Piroska Toth-Tarsoly; University Hospital Of South Manchester NHS Foundation Trust (Manchester): Katie H Mccalman, Peter Alexander; Harrogate District Hospital (Harrogate): Lorraine Stephenson, Thomas Collyer; East And North Herts NHS Trust (Welwyn Garden City): Rhiannon Chapman, Raphael Cooper; Western Infirmary (Glasgow): Russell M Allan, Malcolm Sim; Dumfries And Galloway Royal Infirmary (Dumfries): David W Wrathall, Donald A Irvine; Charing Cross Hospital (London): Kim S Zantua, John C Adams; Worcestershire Royal Hospital (Worcester): Andrew J Burtenshaw, Gareth P Sellors; Royal Liverpool University Hospital (Liverpool): Ingeborg D Welters, Karen E Williams; Royal Alexandra Hospital (Glasgow): Robert J Hessell, Matthew G Oldroyd; Morriston Hospital (Swansea): Ceri E Battle, Suresh Pillai; Frimley Park Hospital (Frimley): Istvan-Kajtor, Mageswaran —Sivashanmugavel; Altnagelvin Hospital (Derry): Sinead C Okane, Adrian Donnelly; Buckinghamshire Healthcare NHS Trust (High Wycombe, Buckinghamshire): Aniko D Frigyik, Jon P Careless; Milton Keynes Hospital (Milton Keynes): Martin M May, Richard Stewart; Ulster Hospital (Belfast): T John Trinder, Samantha J Hagan; University Hospital of Wales (Cardiff): Jade M Cole; Freeman Hospital (Newcastle Upon Tyne): Caroline C MacFie, Anna T Dowling;

Uruguay: Hospital Español (Montevideo): Javier Hurtado, Nicolás Nin; Cudam (Montevideo): Javier Hurtado; Sanatorio Mautone (Maldonado): Edgardo Nuñez ; Sanatorio Americano (Montevideo): Gustavo Pittini, Ruben Rodriguez; Hospital De Clínicas (Montevideo): María C Imperio, Cristina Santos; Circulo Católico Obreros Uruguay- Sanatorio JPII (Montevido: Ana G. França, Alejandro EBEID; CASMU (Montevideo): Alberto Deicas, Carolina Serra

USA: Saint Louis University Hospital (St.Louis): Aditya Uppalapati, Ghassan Kamel; Beth Israel Deaconess Medical Center (Boston): Valerie M Banner-Goodspeed, Jeremy R Beitler; Memorial Medical Center (Springfield): Satyanarayana Reddy Mukkera, Shreedhar Kulkarni; Massachusetts General Hospital (Boston): Jarone Lee, Tomaz Mesar; University Of Cincinnati Medical Center (Cincinnati): John O Shinn lii, Dina_Gomaa; Massachusetts General Hospital (Boston): Christopher Tainter, Jarone Lee; Massachusetts General Hospital (Boston): Tomaz Mesar, Jarone Lee; R Adams Cowley Shock Trauma Center (Baltimore): Dale J Yeatts, Jessica Warren; Intermountain Medical Center (Murray, Utah): Michael I Lanspa, Russel R Miller; Intermountain Medical Center (Murray, Utah): Colin K Grissom, Samuel M Brown; Mayo Clinic (Rochester): Philippe R Bauer; North Shore Medical Center (Salem): Ryan J Gosselin, Barrett T Kitch; AlbanyMedical Center (Albany): Jason E Cohen, Scott H Beegle; John H Stoger Hospital Of Cook County (Chicago, II): Renaud M Gueret, Aiman Tulaimat; Albany Medical Center (Albany): Shazia Choudry; University of Alabama at Birmingham (UAb) (Birmingham, AL): William Stigler, Hitesh Batra ; Duke University Hospital (Durham): Nidhi G Huff; lowa Methodist Medical Center (Des Moines, lowa): Keith D Lamb, Trevor W Oetting; Surgical \& Neurosciences Intensive Care Unit of the University Of lowa Hospitals And Clinics (lowa City, lowa): Nicholas M Mohr, Claine Judy; Medical Center of Louisiana at New Orleans (New Orleans, Louisiana): Shigeki Saito, Fayez M Kheir; Tulane
University (New Orleans): Fayez Kheir; Critical Care Unit of the University Of lowa Hospitals And Clinics (lowa City, lowa): Adam B Schlichting, Angela Delsing; University Of California, San Diego Medical Center (San Diego, Ca): Daniel R Crouch, Mary Elmasri; Uc San Diego Thornton Hospital (La Jolla): Daniel R Crouch, Dina Ismail; University Hospital (Cincinnati): Kyle R Dreyer, Thomas C Blakeman; University Hospital (Cincinnati): Kyle R Dreyer, Dina Gomaa; Tower 3B Medical ICU of Brigham and Women's Hospital (Boston): Rebecca M Baron, Carolina Quintana Grijalba; Tower 8C Burn/Trauma ICU of Brigham and Women's Hospital (Boston): Peter C Hou; Tower 8D Surgical ICU of Brigham and Women's Hospital (Boston): Raghu Seethala; Tower 9C Neurosurgical ICU of Brigham and Women's Hospital (Boston): Imo Aisiku; Tower 9D Neurological ICU of Brigham and Women's Hospital (Boston): Galen Henderson; Tower $11 C$ Thoracic ICU of Brigham and Women's Hospital (Boston): Gyorgy Frendl; Shapiro 6W Cardiac Surgery ICU of Brigham and Women's Hospital (Boston): Sen-Kuang Hou; Shapiro 9E Coronary Care Unit of Brigham and Women's Hospital (Boston): Robert L Owens, Ashley Schomer;

Serbia: Clinical Center of Serbia (Belgrade):Vesna Bumbasirevic, Bojan Jovanovic; ; Military Medical Academy (Belgrade): Maja Surbatovic, Milic Veljovic;

\section{Authors' contributions}

GB, and JGL conceived and designed this ancillary analysis of LUNG SAFE. JGL, GB, TP wer part of the team that conceived, designed and coordinated LUNG SAFE. FM performed data analysis. All authors were were involved in data interpretation. BM and JGL drafted the first version of the manuscript, and all authors critically revised the manuscript and approved the final version.

\section{Funding}

This research was partially supported by the Italian Ministry of University and Research (MIUR) —Department of Excellence project PREMIA (PREcision Medlcine Approach: bringing biomarker research to (linic) and by a Science Foundation Ireland Future Research Leaders Award to Prof Laffey (16-FRL-3845). This LUNG SAFE Study was supported by the European Society of Intensive Care Medicine (ESICM), Brussels, Belgium, by St Michael's Hospital, Toronto, Canada, and by the University of Milan-Bicocca, Monza, Italy.

\section{Availability of data and materials}

The data that support the findings of this study were made available by the European Society of Intensive Care Medicine. Restrictions apply to the availability of these data, which were used after approval was granted by the executive committee for the OPEN-LUNG SAFE initiative. Further details about accessing these data can be found online (https://www.esicm.org/research/ trials/trials-group-2/lung-safe/).

\section{Ethics approval and consent to participate}

This study is an ancillary analysis of the LUNG SAFE database. All ICUs participating in LUNG SAFE obtained ethical approval, patient consent or ethics committee waiver of consent [4]. No further data was collected for this ancillary analysis.

\section{Consent for publication}

Not applicable.

\section{Competing interests}

Prof Laffey reports personal fees from consultancy for Baxter and Cala Medical, and funds to his institution from grants from Science Foundation Ireland, the Health Research Board and others. All other authors attest that they have no conflicts of interest in regard to the subject of this manuscript.

\section{Author details}

${ }^{1}$ Value-Based Health Care Unit, IRCCS MultiMedica, Sesto San Giovanni, Milan, Italy. ${ }^{2}$ Department of Anaesthesia and Intensive Care Medicine, Galway University Hospitals, Galway, Ireland. ${ }^{3}$ School of Medicine, Clinical Sciences Institute, National University of Ireland, Galway, Ireland. ${ }^{4}$ Department of Medicine and Surgery, University of Milan-Bicocca, Monza, Italy. ${ }^{5}$ Department of Emergency and Intensive Care, San Gerardo Hospital, Monza, Italy. ${ }^{6}$ Service de Médecine Intensive-Réanimation, Hôpitaux Universitaires Paris-Saclay, Hôpital de Bicêtre, APHP, Le Kremlin-Bicêtre, France. ${ }^{7}$ Faculté de Médecine Paris-Saclay, Le Kremlin-Bicêtre, France. 
Received: 13 August 2020 Accepted: 11 January 2021

Published online: 13 April 2021

\section{References}

1. Herridge MS, Tansey CM, Matté A, Tomlinson G, Diaz-Granados N, Cooper A, Guest CB, Mazer CD, Mehta S, Stewart TE, et al. Functional disability 5 years after acute respiratory distress syndrome. N Engl J Med. 2011;364(14):1293-304.

2. Azoulay E, Adrie C, De Lassence A, Pochard F, Moreau D, Thiery G, Cheval C, Moine P, Garrouste-Orgeas M, Alberti C, et al. Determinants of postintensive care unit mortality: a prospective multicenter study. Crit Care Med. 2003;31(2):428-32.

3. Sprung CL, Ricou B, Hartog CS, Maia P, Mentzelopoulos SD, Weiss M, Levin PD, Galarza L, de Guardia V, Schefold JC, et al. Changes in end-of-life practices in European intensive care units from 1999 to 2016. JAMA 2019;322:1-12

4. Bellani G, Laffey JG, Pham T, Fan E, Brochard L, Esteban A, Gattinoni L, van Haren F, Larsson A, McAuley DF, et al. Epidemiology, patterns of care, and mortality for patients with acute respiratory distress syndrome in intensive care units in 50 countries. JAMA. 2016:315(8):788-800.

5. Laffey JG, Madotto F, Bellani G, Pham T, Fan E, Brochard L, Amin P, Arabi Y, Bajwa EK, Bruhn A, et al. Geo-economic variations in epidemiology, patterns of care, and outcomes in patients with acute respiratory distress syndrome: insights from the LUNG SAFE prospective cohort study. Lancet Respir Med. 2017;5(8):627-38.

6. Rosenberg AL, Hofer TP, Hayward RA, Strachan C, Watts CM. Who bounces back? Physiologic and other predictors of intensive care unit readmission. Crit Care Med. 2001;29(3):511-8.

7. Azoulay E, Alberti C, Legendre I, Buisson CB, Le Gall JR, European Sepsis G. Post-ICU mortality in critically ill infected patients: an international study. Intensive Care Med. 2005;31(1):56-63.

8. Ensminger SA, Morales IJ, Peters SG, Keegan MT, Finkielman JD, Lymp JF, Afessa B. The hospital mortality of patients admitted to the ICU on weekends. Chest. 2004;126(4):1292-8.

9. Neto AS, Barbas CSV, Simonis FD, Artigas-Raventós A, Canet J, Determann RM, Anstey J, Hedenstierna G, Hemmes SNT, Hermans G, et al.
Epidemiological characteristics, practice of ventilation, and clinical outcome in patients at risk of acute respiratory distress syndrome in intensive care units from 16 countries (PRoVENT): an international, multicentre, prospective study. Lancet Respir Med. 2016;4(11):882-93.

10. Lautrette A, Garrouste-Orgeas M, Bertrand PM, Goldgran-Toledano D, Jamali S, Laurent V, Argaud L, Schwebel C, Mourvillier B, Darmon M, et al. Respective impact of no escalation of treatment, withholding and withdrawal of life-sustaining treatment on ICU patients' prognosis: a multicenter study of the Outcomerea Research Group. Intensive Care Med. 2015;41(10):1763-72.

11. Montgomery AB, Stager MA, Carrico CJ, Hudson LD. Causes of mortality in patients with the adult respiratory distress syndrome. Am Rev Respir Dis. 1985;132(3):485-9.

12. Laffey JG, Bellani G, Pham T, Fan E, Madotto F, Bajwa EK, Brochard L, Clarkson K, Esteban A, Gattinoni L, et al. Potentially modifiable factors contributing to outcome from acute respiratory distress syndrome: the LUNG SAFE study. Intensive Care Med. 2016;42(12):1865-76.

13. Downar J, Delaney JW, Hawryluck L, Kenny L. Guidelines for the withdrawal of life-sustaining measures. Intensive Care Med. 2016;42(6):1003-17.

14. Phua J, Joynt GM, Nishimura M, Deng Y, Myatra SN, Chan YH, Binh NG, Tan CC, Faruq MO, Arabi YM, et al. Withholding and withdrawal of lifesustaining treatments in low-middle-income versus high-income Asian countries and regions. Intensive Care Med. 2016;42(7):1118-27.

15. Fernandez R, Serrano JM, Umaran I, Abizanda R, Carrillo A, Lopez-Pueyo MJ, Rascado P, Balerdi B, Suberviola B, Hernandez G, et al. Ward mortality after ICU discharge: a multicenter validation of the Sabadell score. Intensive Care Med. 2010;36(7):1196-201.

16. Sauro KM, Soo A, de Grood C, Yang MMH, Wierstra B, Benoit L, Couillard P, Lamontagne F, Turgeon AF, Forster AJ, et al. Adverse events after transition from ICU to hospital ward: a multicenter cohort study. Crit Care Med. 2020;48(7):946-53.

\section{Publisher's Note}

Springer Nature remains neutral with regard to jurisdictional claims in published maps and institutional affiliations.
Ready to submit your research? Choose BMC and benefit from:

- fast, convenient online submission

- thorough peer review by experienced researchers in your field

- rapid publication on acceptance

- support for research data, including large and complex data types

- gold Open Access which fosters wider collaboration and increased citations

- maximum visibility for your research: over $100 \mathrm{M}$ website views per year

At BMC, research is always in progress.

Learn more biomedcentral.com/submissions 